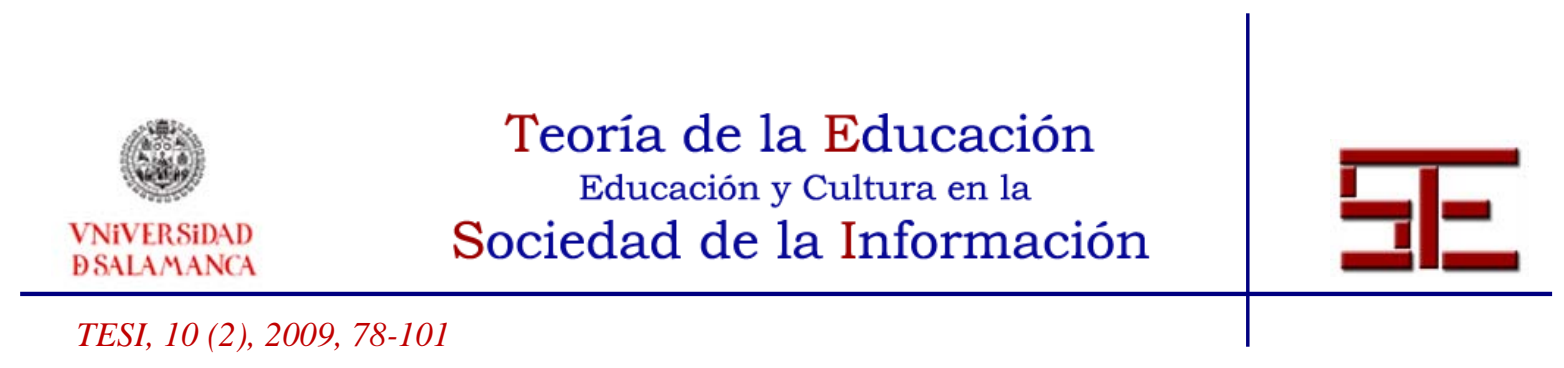

\title{
COMUNIDADES VIRTUALES PRÁCTICAS DE ALFABETIZACIÓN MULTIPLE
}

Resumen: Las tecnologías han transformado nuestra forma de interactuar con los demás. Se están ampliando las dimensiones del proceso participativo en los entornos digitales, como escenarios educativos, gracias a las redes sociales de aprendizaje. En la actualidad se han creado nuevas maneras de comunicarnos y aprender, un colectivo de redes sociales que posibilitan la participación de todos los involucrados, y por tanto también son herramientas de aprendizaje social.

Las posibilidades comunicativas amplían las dimensiones educativas en los escenarios digitales. La participación pasa de ser una posibilidad para convertirse en la fuente principal del proceso de enseñanza-aprendizaje colaborativo. Es necesario la revisión de los enfoques pedagógicos y la creación de metodologías apropiadas al escenario educativo que surge en la modalidad virtual. El desafío actual es la formación y desarrollo de competencias gracias a la alfabetización múltiple que proporcionan las comunidades virtuales de aprendizaje.

Palabras clave: alfabetización, la metodología de la enseñanza, la tecnología en la educación.

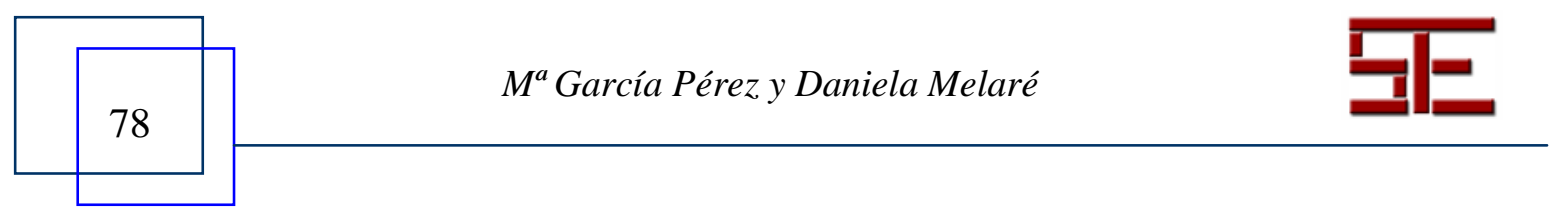




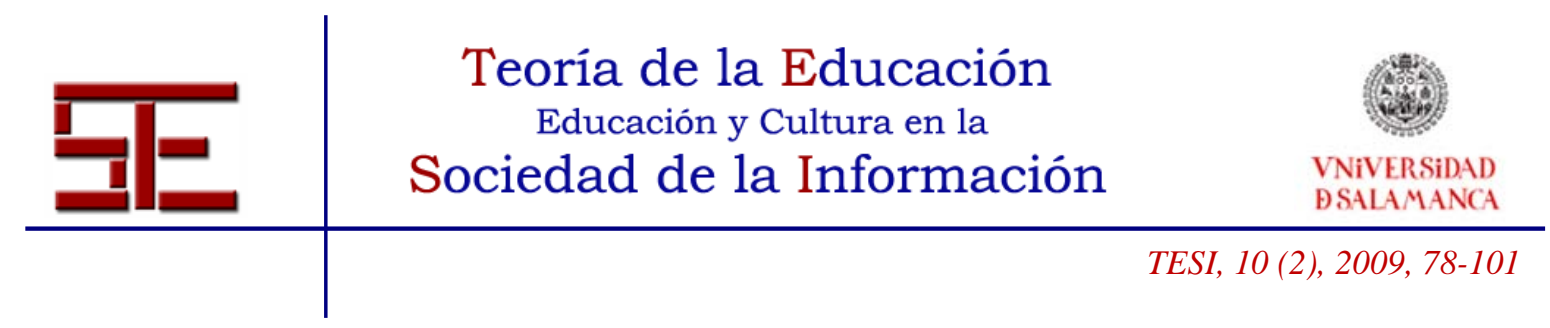

\section{VIRTUAL COMMUNITIES OF PRACTICE MULTIPLE LITERACY}

Abstract: Technologies have transformed the way we interact with others. Are expanding the dimensions of the participatory process in digital environments such as educational settings, thanks to social networks for learning. At the present time have created new ways to communicate and learn, a group of social networks that facilitate the participation of79 all involved, and therefore are also tools of social learning.

Communication possibilities expand educational dimensions in digital scenarios. Participation goes from being a chance to become the main source of teaching and learning collaborative. It is necessary to the review of pedagogical approaches and methodologies to create a scenario, which arises in the virtual mode. The challenge now is training and developing literacy skills through providing multiple virtual learning communities.

Keywords: literacy, teaching methodology, technology in education

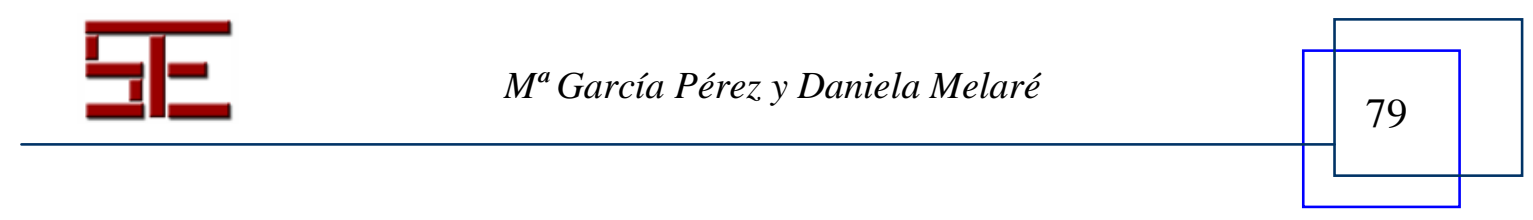




\section{\begin{tabular}{cc}
$\substack{\text { Teoria de la Educación } \\
\text { Educación y Cultura en la } \\
\text { VNIVERSDAD } \\
\text { OSALAANCA }}$ & Sociedad de la Información \\
\hline$T E S I, 10$ (2), 2009, 78-101 &
\end{tabular}}

\section{COMUNIDADES VIRTUALES PRÁCTICAS DE ALFABETIZACIÓN MULTIPLE}

Dra. Daniela Melaré Varros

dmelare@gmail.com

UNOPAR, Brasil.

D. ${ }^{a}$ María García Pérez Calabuig

mgarcia@edu.uned.es

Universidad Nacional de Educación a Distancia.

\section{1.- INTRODUCCIÓN}

En la sociedad actual se ha producido en los últimos años un cambio vertiginoso con la consolidación y generalización de la tecnología en la evolución de la humanidad; lo que ha producido cambios sociales diferentes (Castell, 1998). Las tecnologías de la información y el conocimiento han propiciado un vuelco en los actuales modelos de relación y en el comportamiento global de la sociedad. Se ha acuñado el término Sociedad de la Información como espacio donde todos los agentes sociales deben estar implicados para fomentar el acceso a las tecnologías de manera que dicha información se transforme en conocimiento.

La transformación de la educación es un hecho del que muchos autores han escrito. Nadie pone en duda la importancia de las tecnologías en la educación. Internet y sus herramientas son las claves de un nuevo paradigma educativo. La Red amplía la información, introduce nuevas metodologías didácticas, genera nuevos conocimientos y cambia las relaciones sociales en todos los ámbitos educativos.

Sin embargo, no todos los recursos que se disponen gracias a las tecnologías son aprovechados con calidad y eficiencia educativa. Como señala Feito $(2006,77)$ "por desgracia, nuestra escuela no va más allá de la alfabetización instrumental”, es decir, no solo es necesario que los alumnos conozcan las herramientas básicas de la Red, sino que además se debe fomentar el uso de estas tecnologías para que los individuos adquieran competencias y desarrollen habilidades no solo tecnológicas sino también sociales.

Pero, ¿pueden las redes sociales virtuales crear competencias tecnológicas en las personas? ¿Puede la alfabetización digital ser motor de desarrollo de habilidades

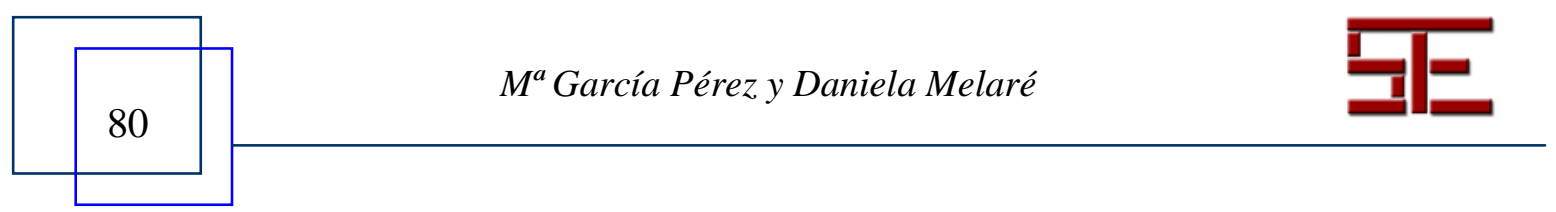




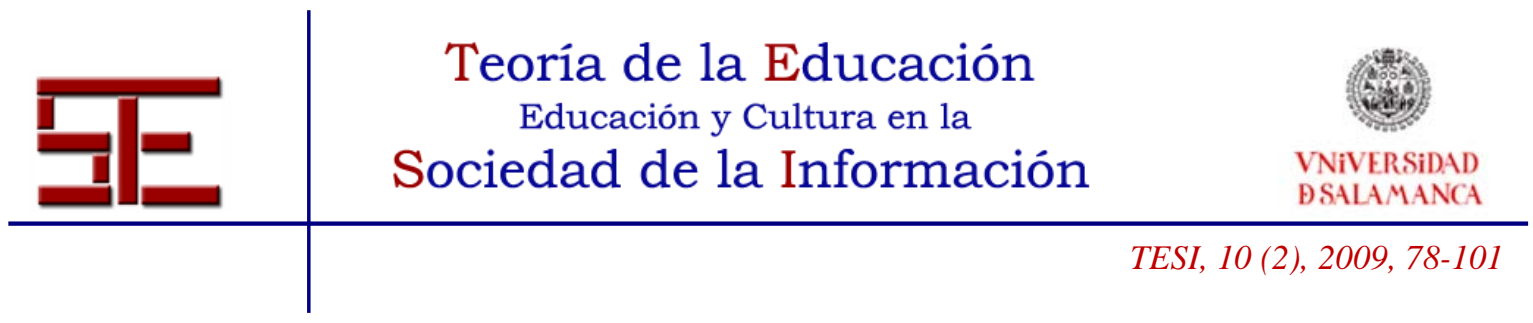

sociales? Las redes sociales virtuales pueden ser la base para explorar y analizar el fenómeno de la alfabetización digital. La creación de nueva cultura con diferentes formas de relacionarse, de comunicarse y de interacción, ha posibilitado que surjan entornos de aprendizaje social como es el ciberespacio (García Aretio, 2007).

\section{2.- REDES SOCIALES Y CIBERESPACIO}

Se habla con excesiva frecuencia de las "redes sociales", sin tener en cuenta cual es su factor innovador y sin explicar en qué se basa su metodología. Las Redes sociales siempre han existido si partimos de la base de que la sociedad se ha relacionado entre sí creando nexos de comunicación a través de diferentes canales. La verdadera revolución de las redes sociales se produjo con la aparición de Internet en todos los ámbitos que nos rodean, lo que ha convertido la naturaleza de la red social en el concepto de redes sociales virtuales.

Si se parte del escaso tiempo y la rapidez de extensión de Internet en la sociedad, podemos asegurar que ha surgido el ciberespacio convertido en una fuente de múltiples herramientas para la creación de redes sociales. Pero, ¿qué significa el ciberespacio?, ¿Cómo influye en las redes sociales?, ¿Qué son las redes sociales virtuales? Estas y otras muchas preguntas podemos hacernos a cerca de nuevos conceptos que barajamos sin definir claramente y sin explicar su alcance educativo.

Considerando este factor social de la Red, de Internet, García Aretio $(2007,121)$ nos adentra en el mundo del ciberespacio como "lugar donde se plasman las relaciones que son posibles gracias a la tecnología de Internet.” Así se explica que este mundo virtual incluye los usos y las prácticas relacionales, y por tanto las redes sociales virtuales. En consecuencia se puede comprender la evolución de las redes sociales como nuevas esferas de transmisión de la información a grandes masas de personas.

Actualmente se están ampliando las dimensiones del proceso participativo en los entornos digitales, como escenarios educativos, gracias a las redes sociales de aprendizaje. Ojeda y otros $(2002,25)$ afirman que "el impacto de las redes de comunicación sobre la formación y la educación supone uno de los mayores cambios que haya tenido lugar en las instituciones educativas, incluso podrá llegar a comparársele con la repercusión que tuvo la imprenta para la generalización del conocimiento". O como señala Viche (2006) se ha creado un nuevo e imaginario

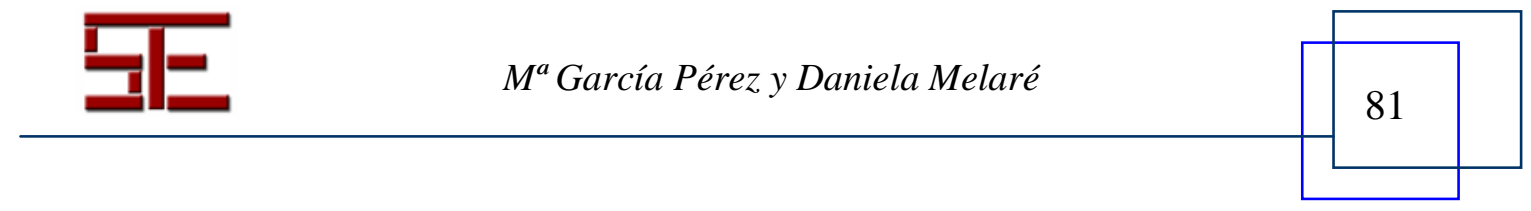




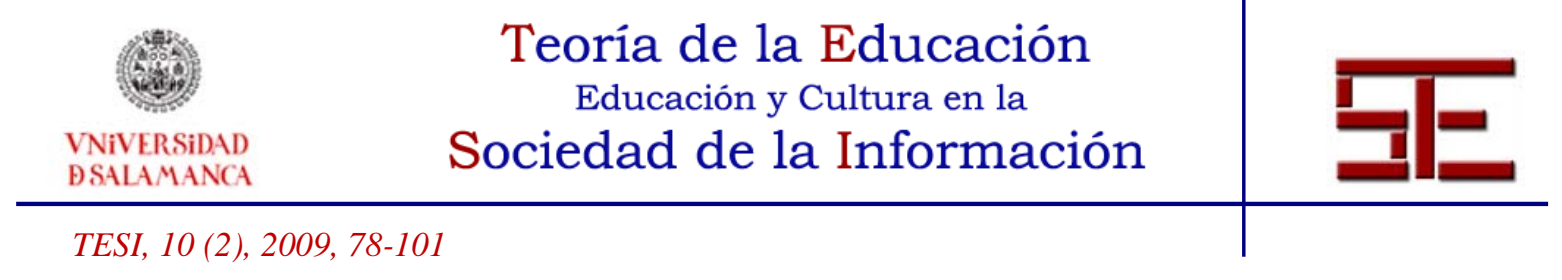

colectivo de redes sociales que posibilitan la participación social, y por tanto también son herramientas de aprendizaje colaborativo.

La participación y colaboración dentro de las redes colaborativas resalta la responsabilidad social que implican la utilización de este procedimiento. El valor de la libertad de elección de los usuarios para poder hacer uso de su derecho de participación y la relación horizontal entre los mismos, otorga un mayor grado de implicación y responsabilidad en el proceso.

Pero existen otros elementos que hay que resaltar dentro de las redes sociales. Indicaba Salinas (1998) que las redes sociales de comunicación ofrecen una educación más flexible, pero también más abierta, más globalizada. Es decir, las personas que se pueden encontrar en una red social no parten de los mismos conocimientos y el concepto social cambia en el trasfondo, ya no se dividen por ciudades o países sino que la red hace que las personas se encuentren interconectadas mundialmente. Se podría profundizar mucho más en las diferencias tecnológicas, ya sean de infraestructura, económicas o de conocimientos informáticos de unos países a otros, o de unas personas a otras aunque se sitúen en el mismo contexto, lo que se ha llamado brecha tecnológica.

Lo más interesante resulta encontrar en una misma sociedad, en un mismo territorio, que coexisten ciudadanos que poseen conocimientos avanzados en el uso de la Web 2.0. compartiendo, produciendo contenidos y estableciendo relaciones sociales a través de la red, mientras que conviven con otros que en muchos casos solo se limitan a la navegación pasiva.

Pero también hay que contar con los datos más actuales sobre el número de usuarios que existen actualmente en España, que según el estudio "Eres online 2008" de Click Seguros un 55 por ciento de la población utiliza Internet entre una y tres horas al día. En la misma línea, la empresa The Cocktail Análisis ha puesto en marcha en el año 2008 un Observatorio sobre la Evolución de las Redes Sociales para conocer la penetración de las principales redes sociales y sus usos. Según los datos aportados por esta investigación algunas redes sociales virtuales como Facebook son más utilizadas por usuarios de edades comprendidas entre 21 a 30 años, otras como Tuenti y Fotolog son más usuales para los usuarios de 14 a 20 años, y las redes de carácter profesional (como Xing y LinkedIn) se vinculan a internautas con edades entre 31 a 40 años. A través de este estudio se puede observar que a pesar de que las redes sociales virtuales están muy extendidas entre los usuarios de Internet, la edad de los mismos marca la tendencia a

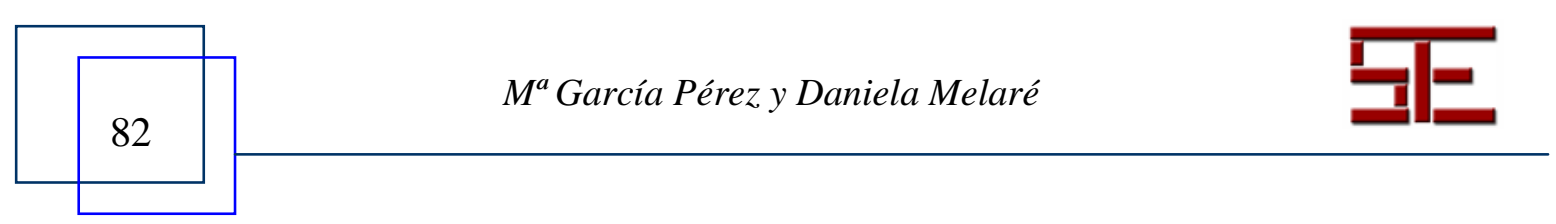




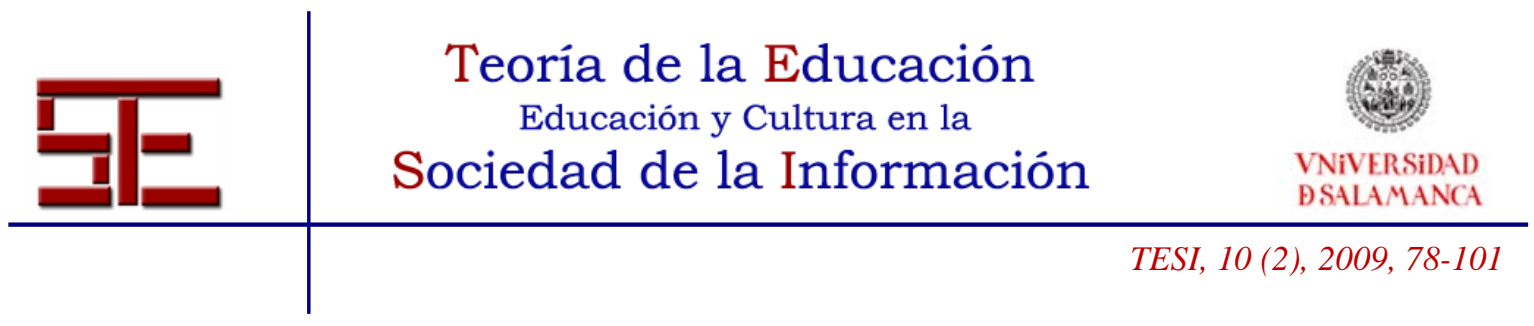

utilizar unas redes o comunidades sociales especializadas. Según Sáez Vacas (2005) la gran multitud de blogs, que trata de millones, "es uno más entre los ámbitos de vida social por el grandioso proceso evolutivo de la tecnología”, pero además, según la investigación de la empresa The Cocktail Análisis $(2008,17)$ "los usuarios de estas redes declaran que actualmente es casi necesario incorporarse a ellas: hay casi un sentimiento de imposición, de obligación social”.

Es fundamental hacer hincapié en que el aprendizaje colaborativo requiere un nuevo perfil de usuario que es coherente y se inserta en el espacio virtual, este nuevo perfil se infociudadanos. Como señala Fumero y Sáez Vacas $(2007,45)$ "el resultado es que a medida que ha aumentado la digitalizad social, interpretado como el grado cuantitativo de penetración de la tecnología en la sociedad, una parte de los ciudadanos va emigrando hacia la condición de infociudadanos -si es que no nacen ya como tales-, o sea, adquieren una mentalidad más digital, mientras que otra parte se mantiene más resistente a ello, o no acepta esa emigración.” Se deduce por tanto que la red se ha convertido en un espacio social donde todos los agentes sociales tienen cabida que interactúan en algunos casos aportando conocimientos, y en otros casos, con una actitud más pasiva.

Dentro de estos infociudadanos se encuentra el colectivo llamado "nativos digitales" y etiquetados también como la "Generación e”. Para Prensky (2001) los nativos digitales son una generación de personas que no solo tienen una total familiaridad con las tecnologías digitales al nacer y crecer con Internet, sino que, además, y basándose en estudios de neurociencias, su forma de pensar, la estructura física misma de su cerebro es diferente a otras generaciones. Genís Roca (2008) analiza el concepto de nativos digitales e identifica sus características culturales propias:

- Dominan los medios de producción digital creando como un juego

- El ciberespacio como terreno de juego

- La red como elemento socializador. Incorporan la red como elemento vertebrador, algo que los inmigrantes digitales no suelen hacer

- Aprenden en red y de la red

- Dan importancia a la identidad digital

- Participan de la conversación a través de diferentes herramientas

Otro grupo de usuarios de las tecnologías son los inmigrantes digitales, que aprendieron con el tiempo a usar las tecnologías, y como señala Estalella (2007) estos sujetos han

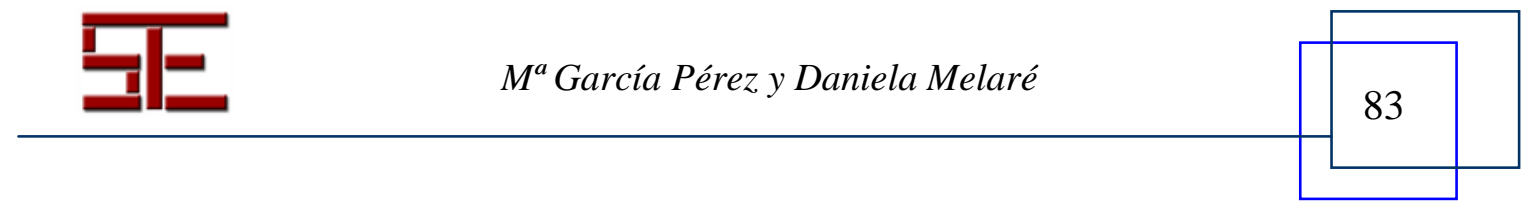




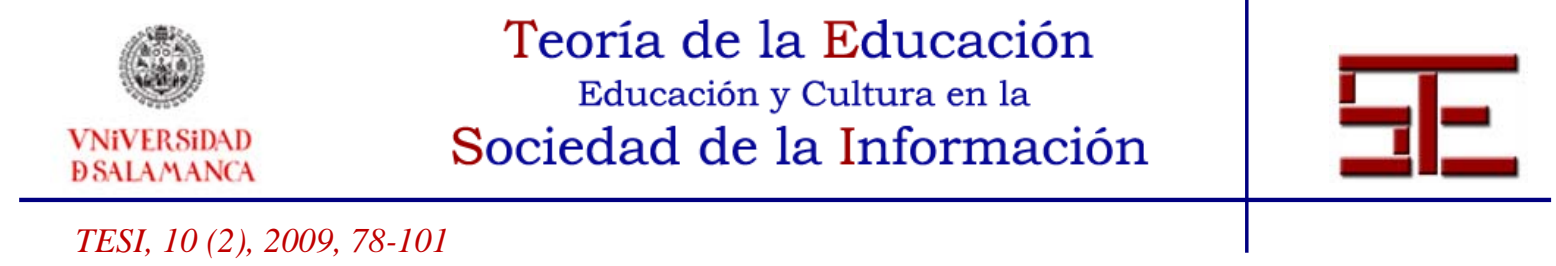

tenido que sumergirse en el mundo digital lo que les ha supuesto "un proceso de inmersión en unas tecnologías que, en el mejor de los casos, les resultaban extrañas." Prensky (2001) resalta cómo comenzaron a utilizar Internet, entre otros factores, gracias al impulso de las administraciones públicas y organizaciones privadas que intentaron con sus programas formativos minimizar el riesgo de la brecha digital con sucesivas olas de alfabetización digital.

Pero hay que tener en cuenta que cada vez más voces se levantan para señalar que la principal diferencia entre los nativos digitales y los inmigrantes digitales no es la edad o la generación en la que se ha nacido. Gasser y Palfrey (2008) resaltan este dato como se recoge en: "Though we frame digital natives as a generation born digital, not all youth are digital natives. Digital natives share a common global culture that is defined not by age, strictly, but by certain attributes and experiences related to how they interact with information technologies, information itself, one another, and other people and institutions. Those who were not born digital can be just as connected, if not more so, than their younger counterparts. And not everyone born since, say, 1982, happens to be a digital native. Part of the challenge of this research is to understand the dynamics of who exactly is, and who is not, a digital native, and what that means.” De ahí sí se puede señalar que tienen una relación diferente con la tecnología y que tienen una forma diferente de pensar, pero el contexto (cultura, sociedad, ambiente, educación, etc.) en el se mueven es lo que condiciona a los sujetos para ser nativos o inmigrantes digitales, por lo menos en la actualidad.

Este nuevo perfil de usuario que utiliza la tecnología también permite que otras relaciones de intercambio y aprendizaje puedan ser caracterizado inicialmente por las comunidades de aprendizaje.

\section{3.- ESCENARIOS EDUCATIVOS EN RED}

Las tecnologías están cambiando de forma radical nuestra forma de interrelacionarnos en cualquier ámbito de actuación humana, y de manera especial, en el campo educativo donde las posibilidades para docentes y estudiantes se multiplican. Ya Salinas en 1998 destacaba la forma en que las tecnologías irrumpieron en los sistemas educativos permitiendo la creación de nuevos espacios de comunicación y articulando procesos sociales a distancia. Los espacios educativos actuales se han visto transformados por la evolución de las tecnologías y otros elementos humanos que han condicionado su desarrollo.

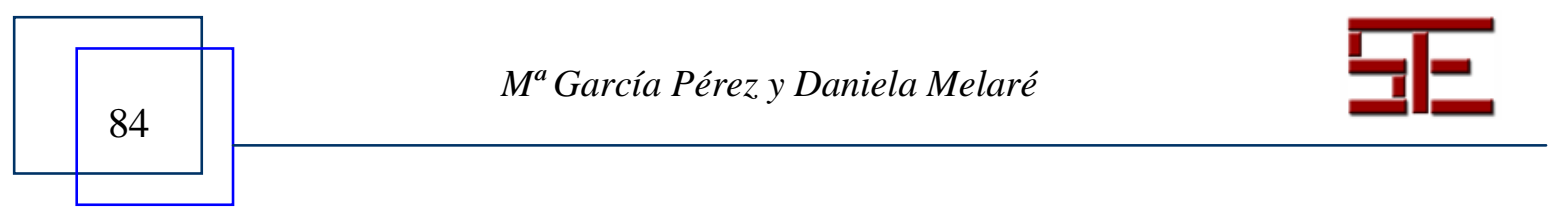




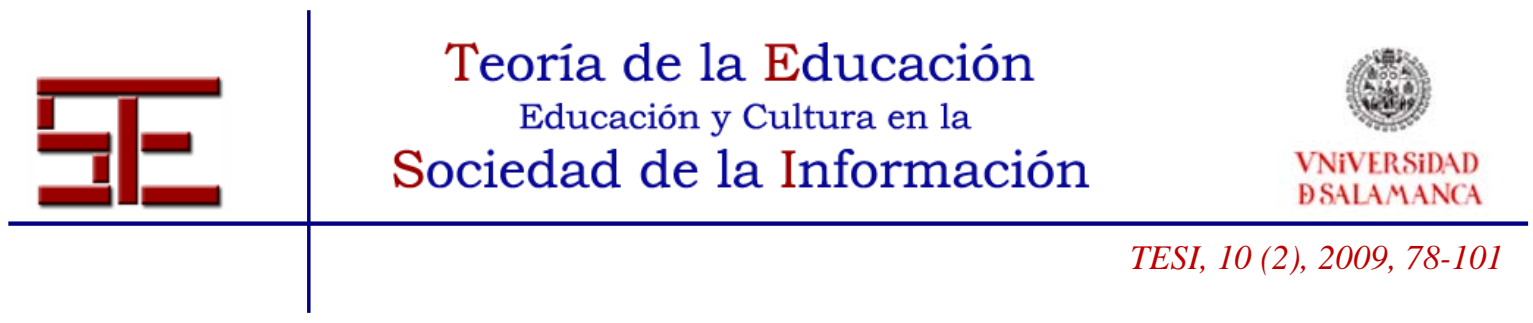

Los escenarios educativos se han ampliado trasladándose a un ambiente virtual, unas veces abandonando la educación formal, otras conjugando educación formal e informal. El encuentro on line se ha caracterizado por estar basado en la libertad práctica que aportan las herramientas de la denominada Web 2.0 para la educación en un sentido amplio. Una de las ventajas formativas de la red es la posibilidad que nos ofrece para la interacción y la comunicación de manera sincrónica y asincrónica entre las personas (Cabero y Gisbert, 2005; Hannum, 2001).

Los ambientes de aprendizaje que surgen en este nuevo modelo planteado, se refieren tanto al impacto que producen las tecnologías en la educación presencial, como el impulso definitivo que ofrece a la modalidad educativa a distancia que posibilita el acceso a recursos de aprendizaje, y establece una comunicación educativa flexible en la distancia y tiempo, novedosa para cualquier modalidad educativa y accesible a la gran mayoría de las personas.

Cabero (2006), al igual que Burbules (2001), plantean que deben considerarse los entornos virtuales de aprendizaje no sólo como un conjunto de herramientas, sino como un escenario en el que se interacciona combinando actividades de comunicación y aprendizaje. Los entornos virtuales suponen un reto para la educación. Proporcionan un soporte fundamental para adecuar la metodología docente a las necesidades de los alumnos, ofreciendo claras ventajas, pero requiere una serie de cambios en el alumnado, profesores e instituciones. Según explica Teare y otros (2002) este ambiente permite ganar flexibilidad e innovar en el campo del aprendizaje, dando mayor libertad al profesor y mayor autonomía para el alumno.

En este nuevo sistema, desaparecen los modelos convencionales de aprendizaje acumulativo y se buscan métodos pedagógicos centrados en el alumno, donde se desarrollen habilidades con las tecnologías de la información y la comunicación, y se pongan en práctica actividades de aprendizaje individualizado, pero sin olvidar las tareas que favorezcan el trabajo colaborativo y una metodología de aprendizaje basado en resolución de problemas.

Las posibilidades comunicativas de Internet amplían las dimensiones educativas en los escenarios digitales. Al considerar la Web 2.0, donde la participación pasa de ser una posibilidad para convertirse en la fuente principal del proceso de enseñanza-aprendizaje colaborativo, es necesario la revisión de los enfoques pedagógicos y la creación de metodologías apropiadas al nuevo escenario educativo que surge en la modalidad

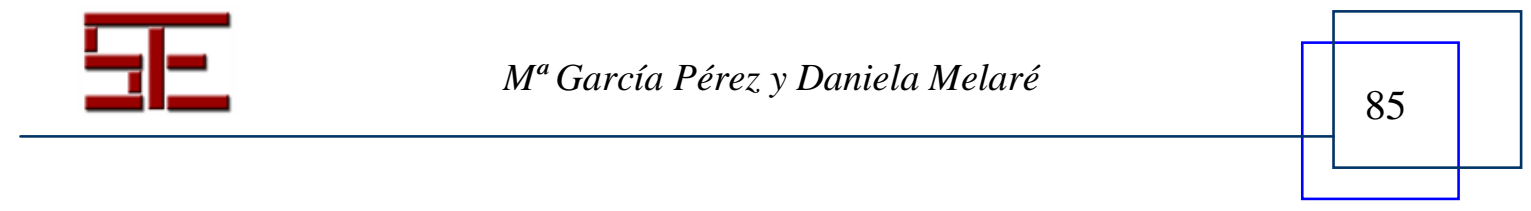




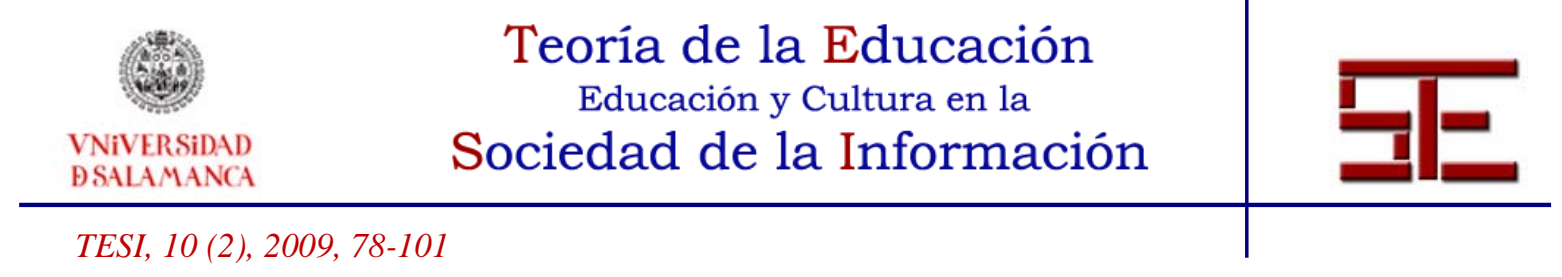

virtual. García Pérez (2007) señala que son nuevos cambios que deben ser evaluados por parte de sus creadores teniendo en cuenta las necesidades del colectivo al que se van a dirigir, por lo que la primera y gran pregunta inicial que se deben plantear antes de utilizar una herramienta u otra es: ¿Qué ventajas docentes voy a conseguir utilizando esta tecnología? ¿Qué metodología debo seguir? ¿Cómo adaptar mis recursos atendiendo la diversidad de los individuos?

\section{4.- COMUNIDADES VIRTUALES DE PRÁCTICA Y DE CONOCIMIENTO}

Henri y Pudelko (2003) afirman de la existencia de diferentes tipos de comunidades. Las comunidades al igual que las redes sociales han evolucionado gracias a las tecnologías. Por tanto, la primera división en el concepto de comunidades radica en Internet. Las comunidades tradicionales están sujetas a un espacio y tiempo concretos, mientras que las llamadas comunidades virtuales son dependientes de la Red, pero además su característica más relevante se basa en la interacción social y el aprendizaje virtual.

El cumplimiento del objetivo alcanzado con la democratización de Internet, fruto de la participación social en la Red, provoca que las comunidades sociales de aprendizaje donde todos sus integrantes interactúan creando conocimiento crezcan y ofrezcan nuevos recursos más integradores y que mejoran la calidad educativa virtual. En el anterior apartado tratábamos el tema de los nativos digitales y de los inmigrantes digitales como elementos principales que hay que tener en cuenta, ya que son los agentes receptores y productores de la comunicación, información y del proceso de enseñanza y aprendizaje.

Esta formación cada vez más extendida, es la propia consecuencia del desarrollo de la Red en la sociedad, y a su vez es la propia sociedad la que desarrolla la Red con su participación y contribución libre.

En el siguiente gráfico podemos ver la situación actual que atraviesa la Web 2.0., que a pesar de seguir su evolución (algunos autores ya hablan de la Web 3.0.) mantiene estos elementos planteados comunes en cualquier momento educativo como un espacio virtual de aprendizaje:

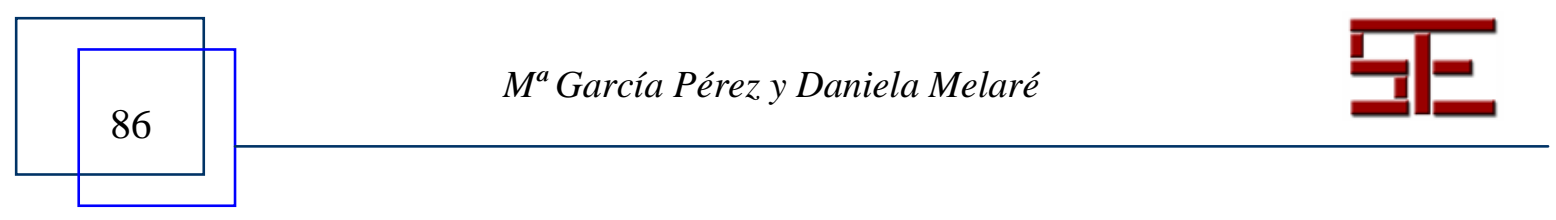



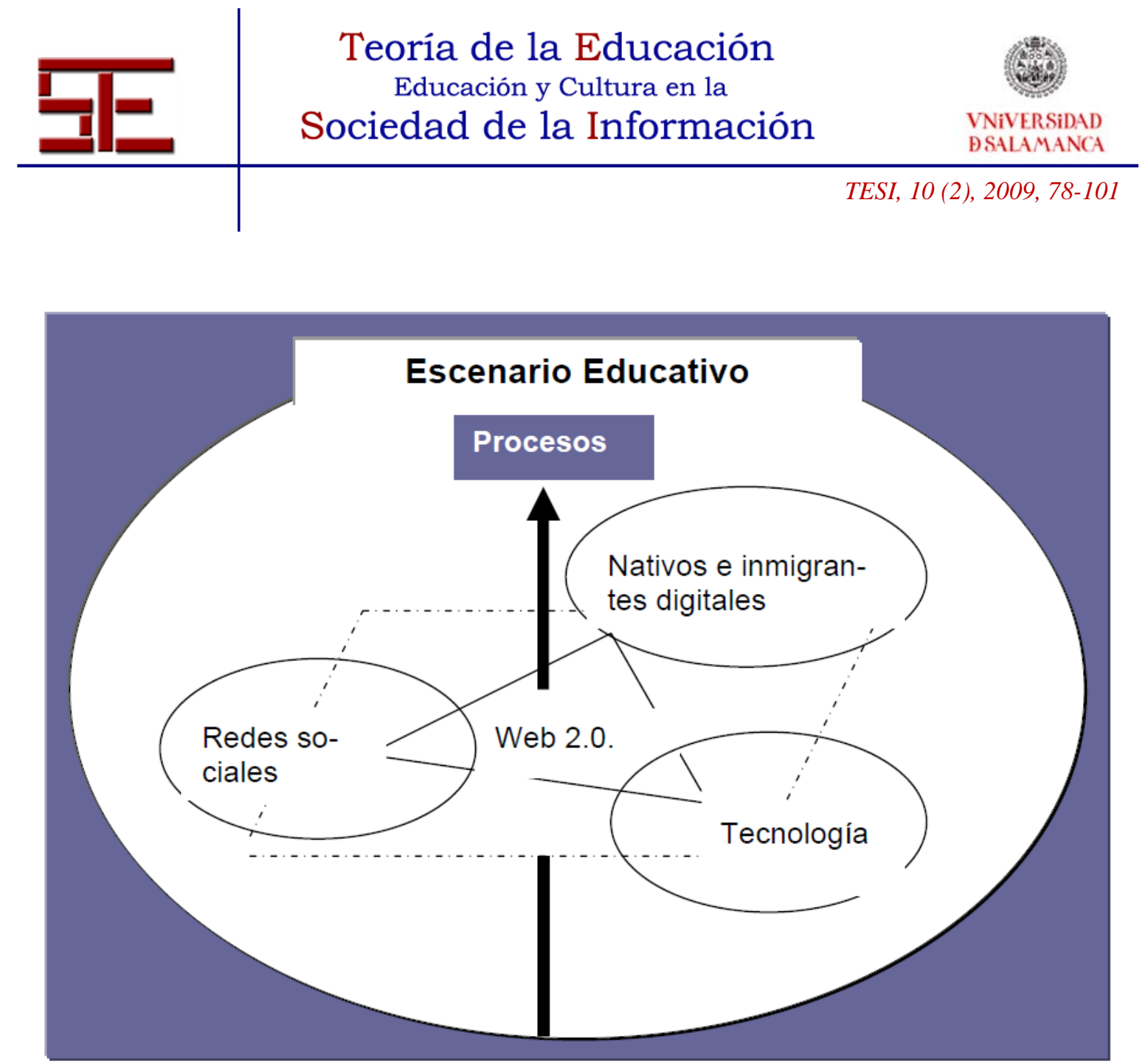

Fuente: Cerezo, J. M. (coord); Fumero, A.; Roca, G.; Saez Vas, F. (2006). Web 2.0. Fundación Orange España (pp. 25)

De esta forma se producen dos fenómenos, por una parte se comparten con otros usuarios los conocimientos en las prácticas educativas, y por otra parte, los usuarios crean herramientas para gestionar los contenidos formativos.

Cualquier experto en las áreas de formación deberán comenzar preguntándose por las limitaciones y posibilidades que las herramientas de comunicación en línea ofrecen a sus programas formativos, así como las posibilidades y limitaciones de los modelos tecnopedagógicos (Coll, 2004). Pero sobre todo se debe analizar cuáles son las herramientas que fomentan la alfabetización digital impulsando el aprendizaje colaborativo.

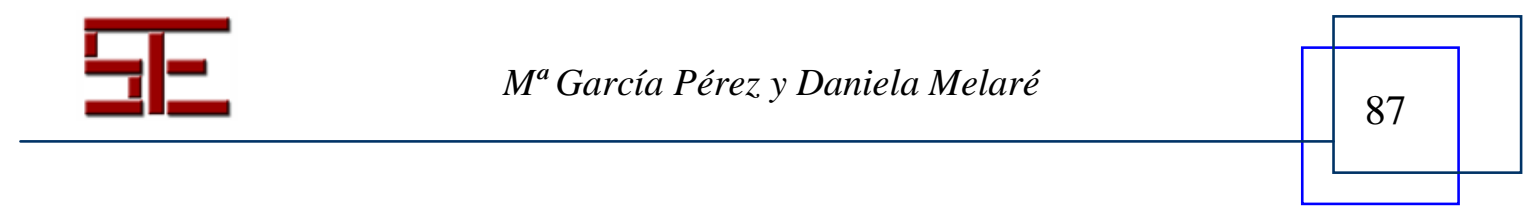




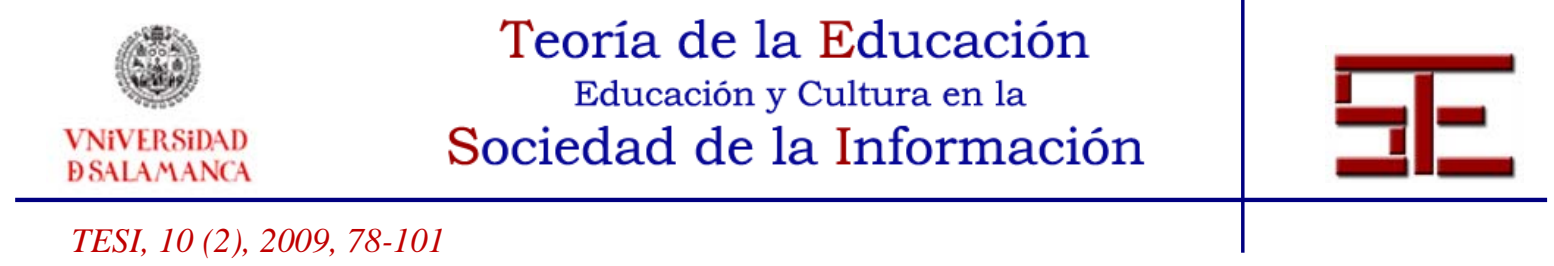

Los profesores innovan con nuevas herramientas digitales, mientras que los alumnos ya sean nativos o inmigrantes, demandan este tipo de métodos en las aulas, ya sean presenciales o virtuales. La metodología del aprendizaje colaborativo, que se apoya en la interacción y el intercambio de información y conocimiento entre los participantes, se ha convertido en una de las metodologías más significativas y más utilizadas en la actualidad (Román, 2004; Martínez y Prendes, 2006).

Cabero (2006) entiende que las comunidades virtuales de aprendizaje son comunidades de personas, que comparten unos valores e intereses comunes comunicándose a través de diferentes herramientas que nos ofrecen las redes telemáticas. Son entornos donde se encuentran las personas que lo forman y destacan los aspectos de sociabilidad e interacción social entre los participantes, no el aislamiento sino la colaboración. Y desde esta sencilla definición Wenger (2001) aporta la connotación educativa planteando que las comunidades generan aprendizaje siendo un lugar privilegiado para la adquisición de conocimientos y para la transformación de los saberes concibiendo nuevas ideas entre todos los involucrados.

Dentro de los pilares de la educación en la sociedad del conocimiento, y más aún si partimos de las comunidades de aprendizaje, uno de los principales retos en este entorno es presentar mayores oportunidades para sacar partido a las infotecnologías para nativos e inmigrantes. Es necesario, por tanto, eliminar las barreras sociales que existen para que la brecha tecnológica desaparezca y no sea palpable en la educación virtual. Se debe apoyar a estos usuarios con la innovación y un sistema eficaz que cambie los modelos pedagógicos en la modalidad virtual, para entender que hay una integración social de todos los agentes implicados.

Antes de comenzar al análisis metodológico que se plantea en este artículo es necesario conocer y reflexionar sobre la base teórica del concepto de alfabetización múltiple. Es importante poner de manifiesto, de una manera constructiva, el mundo digital y su relación con la alfabetización tanto para expertos en el área como para profesionales de otros ámbitos.

\section{5.- ALFABETIZACIÓN MÚLTIPLE}

Como se ha dicho, las tecnologías trajeron consigo muchos cambios, en particular, transformaron y contribuyeron a crear nuevas posibilidades educativas. En la declaración de la Asamblea General de las Naciones Unidas (1990, ‘Año Internacional

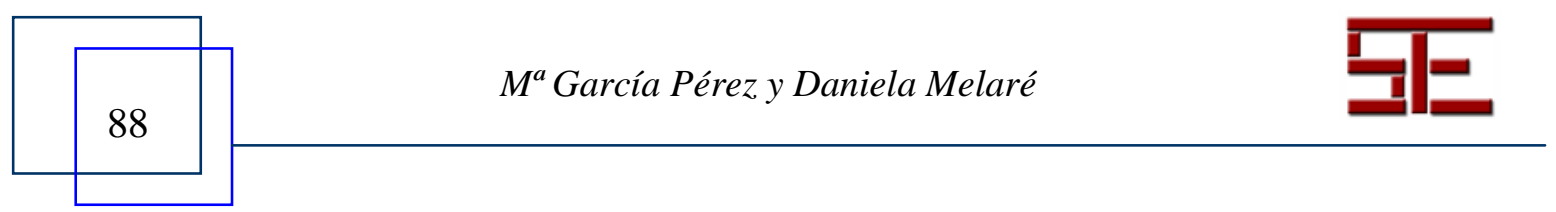




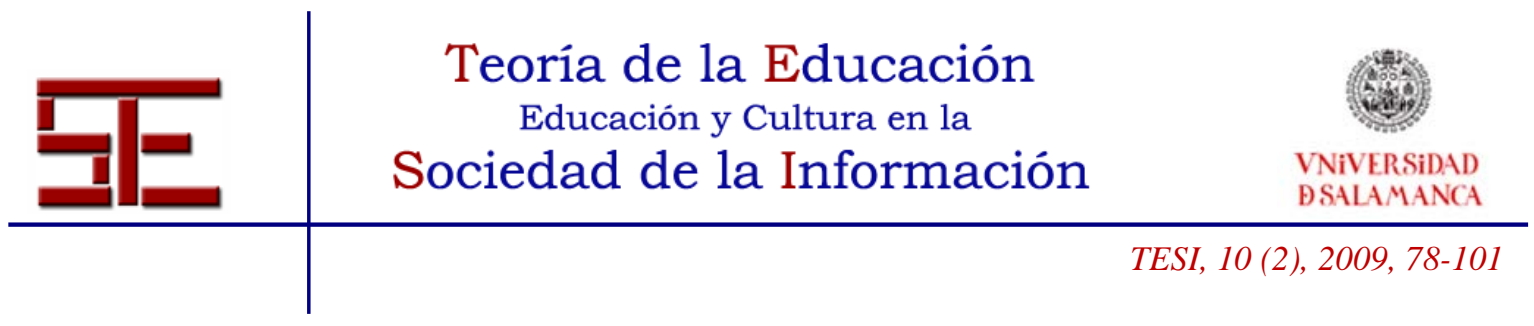

de la Alfabetización') se definió el término de alfabetización ampliando el concepto a todos los significados que engloba. Como nos recuerda Bawden (2002, p. 364) este acontecimiento marcó el comienzo de un programa de diez años para la reducción del analfabetismo, pero también despertó un interés mayor hacia el significado de alfabetización en la Sociedad de la Información. Se podría hablar entonces del surgimiento de la alfabetización tecnológica.

Unos años después, en el informe de la Organización para la Cooperación y el Desarrollo Económicos (OCDE), The Knowledge-based Economy (1996), ya se preveía que el desarrollo de la economía del conocimiento debía partir desde el aprendizaje continuo ylas competencias informativas. Y un año más tarde, en el proyecto DeSeCo (Definition and Selection of Competencies: Theoretical and Conceptual Foundations) se hablaba y se reconocía la alfabetización en tecnologías como una de las "competencias clave” de la competitividad económica y el desarrollo humano. También los estudiosos se percataron de esta situación cambiante y de la evolución del concepto, por eso, expertos de la talla de Arp (1990), Breivik (1991) y Behrens (1994), trataron la naturaleza cambiante del concepto de alfabetización en la sociedad de la información.

Con el paso del tiempo el concepto inicial de alfabetización se transformó llegando a ser mucho más que la simple capacidad de leer y escribir. En la actualidad se ha complementado haciendo referencia a la necesidad del desarrollo de destrezas para manejar la creciente complejidad de la información que proporcionan las tecnologías. Y como señala Acín $(2006,125)$ "la finalidad de la alfabetización digital es provocar una transformación social”, es decir, crear un espacio donde el ciudadano 2.0 pueda participar desarrollando sus capacidades.

Belluzzo $(2004,18)$ afirma que, en la sociedad de la información en la cual estamos insertos, "es necesario que el acceso y uso de la información sea extensible a toda la población”. Sin embargo, el exceso de información disponible en Internet puede ser motivo de exclusión digital, y por tanto social, y de ahí surge la importancia de formar a los individuos en este ámbito. Por esta razón, dicha formación debe ir orientada hacia la madurez digital. Las personas deben saber discernir cuáles son sus necesidades de información, dotarles de herramientas que les permita la eficacia en la búsqueda, acceso, evaluación y organización de los datos que puedan ser transformados en conocimiento. Con lo cual, la alfabetización en tecnologías debe ser una acción dirigida a la integración y el desarrollo de las habilidades y competencias a través del

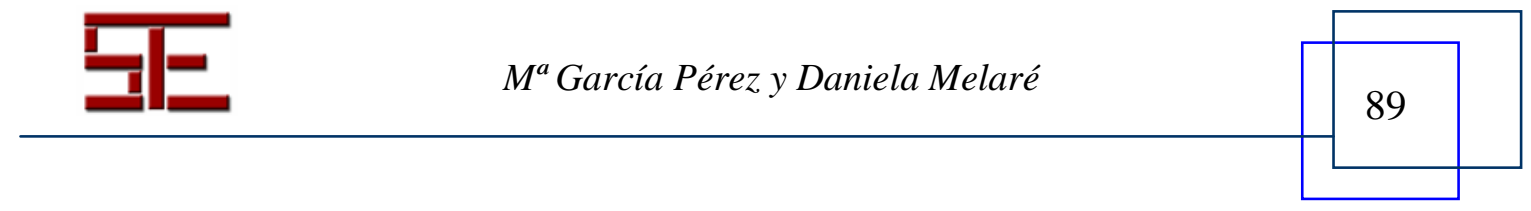




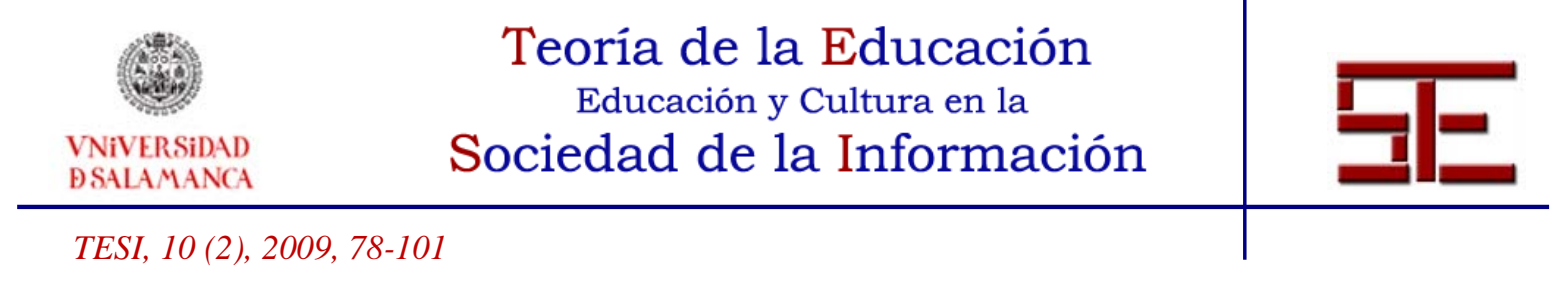

aprendizaje en el uso de las herramientas tecnológicas. Y por tanto, los elementos que constituyen este aprendizaje se basan en las aptitudes y habilidades.

Para tratar la complejidad del entorno actual se necesita partir de un concepto de alfabetización más amplio y complejo. Debe incluir todas las alfabetizaciones basadas en destrezas, pero no limitarse a ellas, sino en el significado que aportan cada una en su conjunto. La alfabetización se compone de cuatro áreas básicas que se deben desarrollar para alcanzar los objetivos propuestos: la alfabetización informacional, alfabetización mediática, alfabetización digital y alfabetización múltiple.

\section{1.- Alfabetización Informacional: origen y significado}

Según Dudziak (2001), el término de Alfabetización Informacional (en inglés, Information Literacy) tiene su origen en la aparición de la sociedad de la información, caracterizada por el rápido crecimiento de la información disponible y sus cambios causados por la tecnología utilizada para generar, difundir, el acceso y el uso de esa información. En el año 2003, y según la Declaración de Praga, se reconoció como uno de los derechos básicos de la Humanidad para el Aprendizaje a lo largo de la vida.

La Alfabetización Informacional (también llamada por las siglas ALFIN) ha sido definida por multitud de estudiosos. Byrne (2005, p. 10) lo definió como "el conjunto de capacidades, habilidades, conductas y actitudes que trasciende el medio utilizado para el intercambio de la información que le facilita su propia eficacia” Dudziak (2001) complementa el concepto relacionándolo con el aprendizaje y la capacidad de crear sentido a partir de la información. Pero sin duda la definición que engloba y concibe el significado y alcance es la de Belluzzo (2005) que lo percibe como:

"[...] processo contínuo de interação e internalização de fundamentos conceituais, atitudinais e de habilidades específicas como referenciais à compreensão da informação e de sua abrangência, em busca da fluência e das capacidades necessárias à geração do conhecimento novo e sua aplicabilidade ao cotidiano das pessoas e das comunidades ao longo da vida”. Belluzzo (2005, p.99)

Por tanto, las competencias desarrolladas por los individuos no solo se basan en el uso de la información, sino que también adquieren las capacidades para discernir su necesidad, el lugar dónde encontrar la información, y conocen el procedimiento para

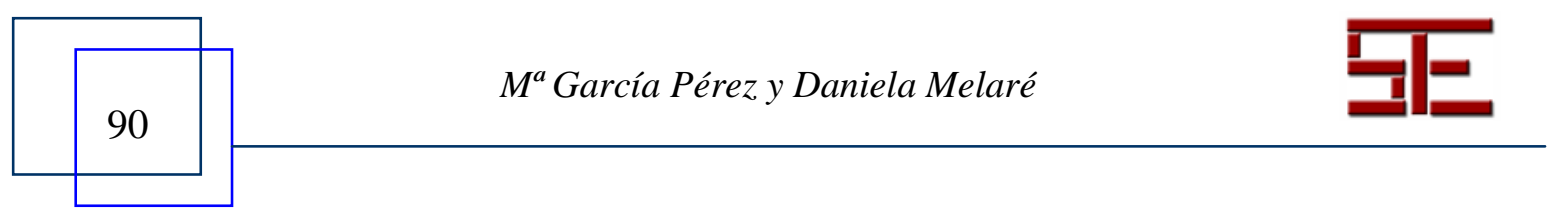




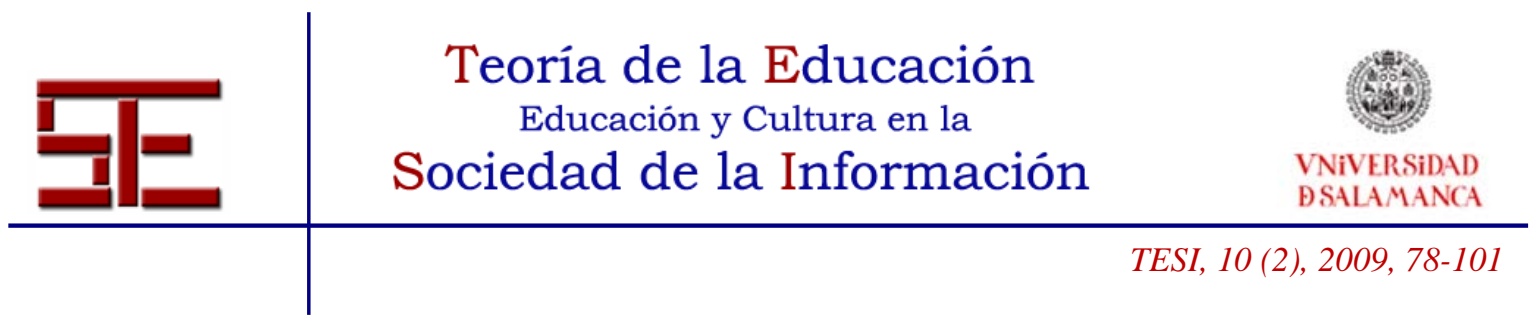

evaluar y seleccionar el conocimiento. Los componentes que apoyan este concepto son los siguientes: el proceso de búsqueda, el aprendizaje activo, el aprendizaje independiente, pensamiento crítico, el aprender a aprender y aprender durante toda la vida.

Si nos referimos al campo educativo, la alfabetización Informacional debe capacitar al individuo para alcanzar y desarrollar habilidades mentales tales como: la comprensión, interpretación, evaluación, organización, síntesis, aplicación, uso y la comunicación de la información.

\section{2.- Alfabetización en medios de comunicación}

La alfabetización mediática es la habilidad para producir, crear y comunicar con éxito la información a través de los medios de comunicación.. Utiliza las imágenes, sus significados y toda la estructura de los medios de comunicación. Bawden (2002, 369) profundizando en sus significado lo define como "término usado para connotar una actitud crítica en la evaluación de la información que se obtiene a través de los medios de comunicación de masas: televisión, radio, periódicos y revistas, y (cada vez más) Internet”. Aunque se ve una clara diferencia con la alfabetización informacional, la mayoría de los autores coinciden en la interrelación entre estos conceptos, y por tanto prefieren considerar la alfabetización en medios como un componente de la Alfabetización informacional.

Se pretende dotar a los individuos de las competencias necesarias para comprender la imagen de lo leído y su significado. Uno de los objetivo de la alfabetización informacional es aprender a evaluar críticamente la combinación de imágenes elegidas. La televisión y otros medios es esencial en este tipo de alfabetización (Siqueira, 2005). Los medios de comunicación se usan de diversas maneras para alcanzar el objetivo. Para ello, es posible utilizar los medios de comunicación puestos a disposición del proceso educativo. Teniendo en cuenta estos aspectos, el tema de la usabilidad y la interactividad del lector con los materiales digitales nos permiten entender la visión del lector a través de la teoría de la facilidad de uso, o de la alfabetización digital.

\section{3.- Alfabetización Digital}

El término alfabetización digital ha sido utilizado desde los años 90 para referirse a la capacidad de los sujetos para leer y entender textos de hipertexto y multimedia. Por

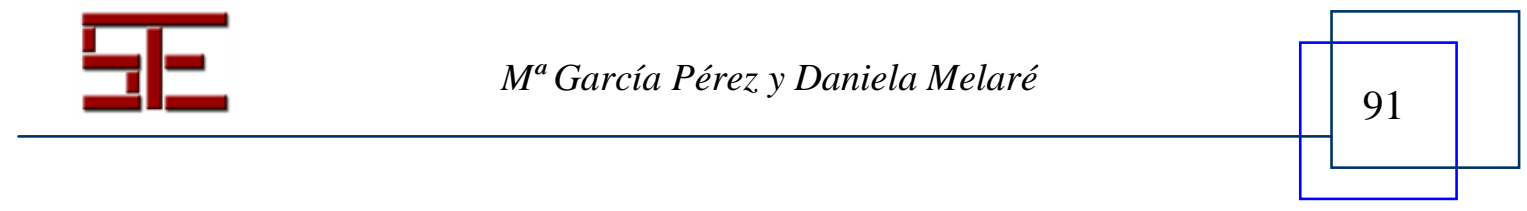




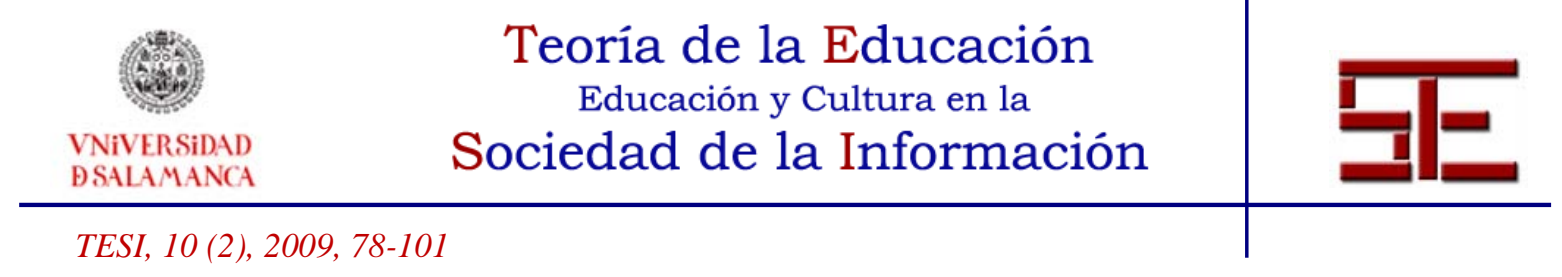

tanto, implica la capacidad para entender información cualquiera que sea el formato en que se presente. Gilster (1997) lo definió como la capacidad para comprender y utilizar las fuentes de información cuando se presentan a través del ordenador.

La alfabetización digital incluye el dominio de un conjunto de habilidades centrales que los sujetos deben desarrollar. Y además no solo debe la habilidad de encontrar la información, sino que también debe desarrollar la habilidad para utilizar esta información en su vida. Esta doble naturaleza de la alfabetización digital permite al usuario comunicarse, difundir y publicar su conocimiento.

Para Casado (2006) la alfabetización digital es un proceso continuo cuyo trasfondo está referido no sólo a la información, sino también al conocimiento. Estar alfabetizado digitalmente es conseguir la capacidad de interactuar inteligentemente con las tecnologías. La alfabetización digital y la alfabetización virtual son dos conceptos muy relacionados que apenas difieren.

Por otra parte la alfabetización digital se relaciona con el concepto de usabilidad debido a que se refiere al mundo de la Web 2.0. En este contexto se diseña la acción educativa con el objetivo de hacer los sitios web más prácticos y fáciles de usar a fin de poder llegar a todos los individuos que van a ser alfabetizados digitalmente.

\section{4.- Alfabetización múltiple}

Aunque Bhola (1997) ya utilizó este término para definir un conocimiento más rudimentario dentro de un área de conocimiento concreto. En nuestro contexto la alfabetización múltiple se refiere un paso más allá, es el desarrollo de destrezas que conjugan el uso de las tecnologías, de la información y los medios de comunicación.

Montes de Oca (2008, 92) define el término como "las destrezas, conocimientos y aptitudes necesarias para poder vivir y convivir en la sociedad de la información, así como capacitarse para superar la llamada brecha digital y lograr la igualdad de oportunidades en el ámbito social y laboral". Es decir, como los tres tipos de alfabetización están interrelacionadas, estos a su vez, en la Web 2.0 interactúan formando un conjunto más amplio de destrezas, de resolución de problemas, de información, con la Alfabetización múltiple en el punto de intersección. Por tanto, el concepto engloba a toda la sociedad, tanto a los nativos como a los inmigrantes digitales, ya que las destrezas y conocimientos de unos y otros no se ven como

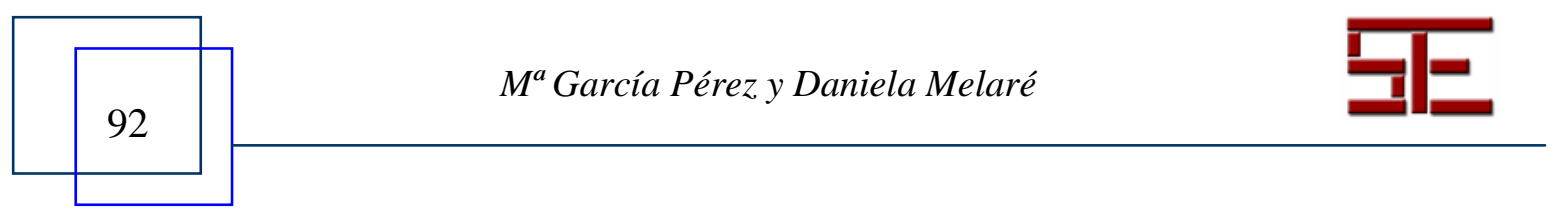




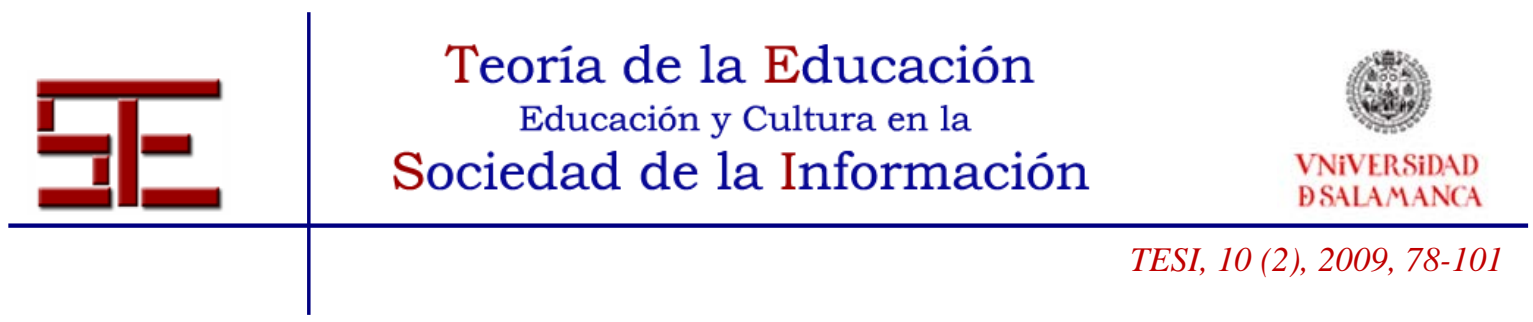

diferencias significativas e inalcanzables, sino como puntos de unión para alcanzar un desarrollo personal en la sociedad de la información y el conocimiento.

Penrod (2008) afirma que la alfabetización digital (literacy 2.0) ofrece a los estudiantes la posibilidad de buscar más información, implicarse en debates y afrontar tareas creativas. Pero la alfabetización múltiple además prepara al individuo en la utilización del pensamiento y en la valoración de los significados sociales, culturales y políticos del acceso, uso y difusión de la información. Si se analiza la situación con mayor detenimiento podemos comprobar que los usuarios de la red no solo utilizan la alfabetización digital, sino la alfabetización múltiple en sus relaciones sociales desplegando todas sus destrezas y capacidades dentro de la Web 2.0 que aglutina todas las tipologías de alfabetización.

En esta misma línea, Montes de Oca $(2008,18)$ analiza el concepto de la alfabetización múltiple entendiendo que "las nuevas competencias requeridas serán reemplazadas en poco tiempo por otras todavía más nuevas”. Por esta razón nos planteamos que no solo habrá cambios estructurales en los comportamientos de las personas a través de la Red, sino que eso contraerá la existencia de una nueva metodología docente que provoque el surgimiento de nuevas competencias necesarias para los tutores.

\section{6.- DESARROLLO DE COMPETENCIAS MULTIPLES A TRAVÉS DE LAS REDES SOCIALES}

De forma general, Bawden (2002, 400) profundiza en las habilidades que se adquieren y afirma que para "ser auténticamente competente en el mundo digital significa poseer las destrezas para descifrar imágenes y sonidos complejos además de los matices sintácticos de las palabras”.

Como antes se decía, la alfabetización múltiple es el resultado de la conjunción de todos los tipos de alfabetizaciones que se dan en la Web 2.0, donde no solo importa los conocimientos de informática y sus usos, sino que resalta su papel socializador y colaborativo para el proceso de enseñanza y aprendizaje. Por esta razón, la alfabetización múltiple, al igual que la alfabetización digital, desarrolla las destrezas necesarias para el uso de aplicaciones de la tecnología para transformar los conocimientos en nuevas informaciones, datos e imagen. Pero también por otra parte, es un proceso de comunicación que trabaja con el lenguaje visual y sus nuevos códigos virtuales, al igual que la alfabetización en medios de comunicación.

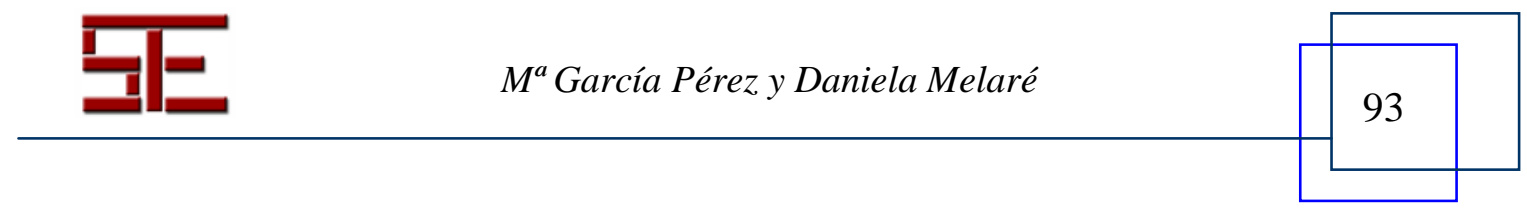




\begin{tabular}{ccc}
$\begin{array}{c}\text { Teoría de la Educación } \\
\text { Educación y Cultura en la } \\
\text { VNiVERSIDAD } \\
\text { DSALAMANCA }\end{array}$ & Sociedad de la Información \\
\hline TESI, 10 (2), 2009, 78-101 &
\end{tabular}

La alfabetización múltiple implica que los sujetos desarrollan la capacidad de identificar, acceder, y utilizar la información procedente de las redes sociales virtuales en cualquiera de las modalidades o en su conjunto. Las redes sociales virtuales capacitan a los individuos proporcionándoles un conjunto integrado de destrezas y de conocimientos informáticos. Los usuarios de la Red comprenden el papel de información no como una simple búsqueda de la misma, sino que desarrolla actitudes personales (perseverancia, minuciosidad, habilidad para la resolución de problemas, entre otras) en la manipulación de esa información a través de la variedad de los recursos de la red.

Según Belluzzo (2005) las competencias que se adquieren se enfocan a tres puntos clave dentro del aprendizaje:

- Digital - con énfasis en la tecnología de la información y la comunicación.

- La información en sí - énfasis en los procesos cognitivos.

- Social - énfasis en la inclusión social, consistente en una visión integrada del aprendizaje permanente y el ejercicio de la ciudadanía.

A partir de las dimensiones que figuran, todos deben tener responsabilidad y ser educados para afrontar los retos de la sociedad, la adquisición de conocimientos en las siguientes esferas principales:

\begin{tabular}{|l|l|}
\hline $\begin{array}{l}\text { Desarrollo de procesa- } \\
\text { mientos de datos e in- } \\
\text { formación }\end{array}$ & $\begin{array}{l}\text { Posibilita la utilización de programas, aplicaciones y técni- } \\
\text { cas adecuadas a los datos y a la información disponible. }\end{array}$ \\
\hline $\begin{array}{l}\text { Conocimientos básicos } \\
\text { de hardware y software }\end{array}$ & $\begin{array}{l}\text { Conocimiento y aprovechamiento de los recursos tecnoló- } \\
\text { gicos disponibles. Eficiencia y eficacia en el desarrollo de } \\
\text { las personas. Posibilita la obtención de nuevos conocimien- } \\
\text { tos. }\end{array}$ \\
\hline $\begin{array}{l}\text { Impacto social resultante } \\
\text { del uso de ordenadores y } \\
\text { otras tecnologías }\end{array}$ & $\begin{array}{l}\text { Examina los conceptos, usos y consecuencias de las tecno- } \\
\text { logías de la información y la comunicación en los modos en } \\
\text { que están siendo utilizadas para la interacción de las perso- } \\
\text { nas, las organizaciones y los diferentes contextos culturales. }\end{array}$ \\
\hline $\begin{array}{l}\text { Formas de utilizar las } \\
\text { TIC en diferentes áreas } \\
\text { de conocimiento }\end{array}$ & $\begin{array}{l}\text { Adoptando una postura multifuncional y multidisciplinar en } \\
\text { la gestión de la información y la comunicación. }\end{array}$ \\
\hline
\end{tabular}

Cuadro 1 - Dimensiones de conocimiento. El poder de la información en la sociedad contemporánea. Fuente: BELLUZZO (2005, p.96).

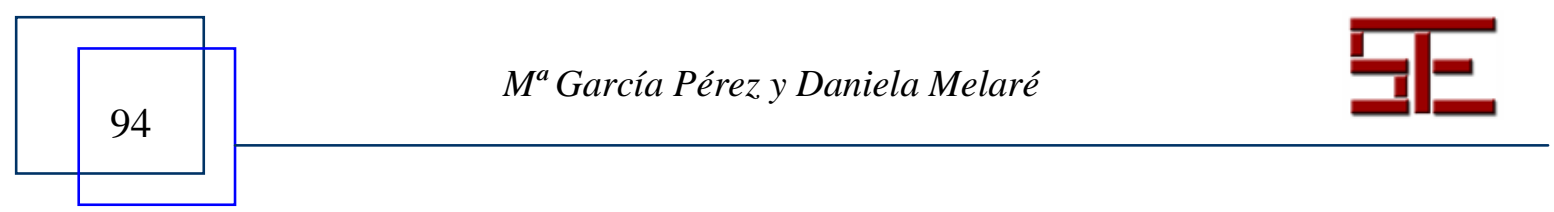




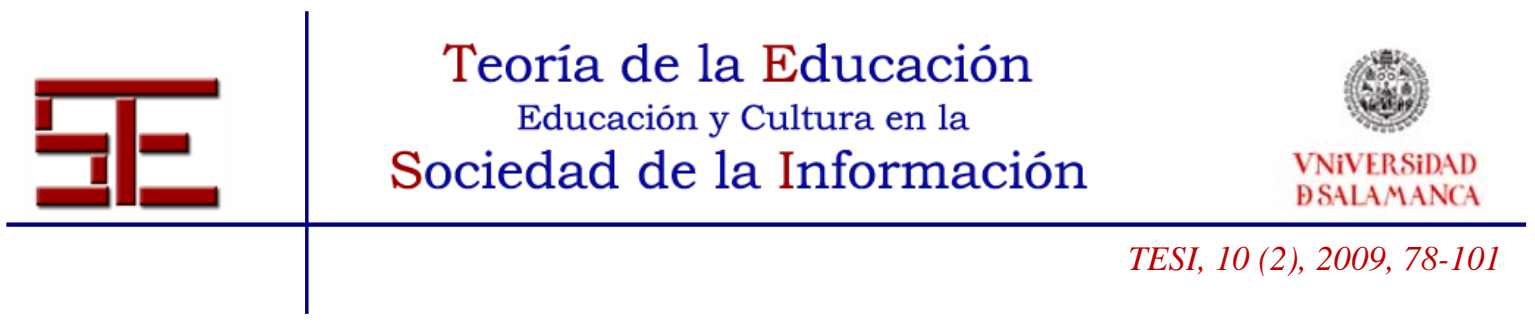

Al igual que Belluzzo, Gros (2008, 272) entiende que para conseguir un modelo educativo integral para la alfabetización requiere el desarrollo de diferentes dimensiones:

- Dimensión instrumental (conocimiento práctico en el uso del software y el hardware).

- Dimensión cognitiva (desarrollo de las competencias necesarias para buscar, seleccionar, analizar y comprender la información).

- Dimensión actitudinal (desarrollo de un conjunto de actitudes ante las tecnologías).

- Dimensión axiológica (toma de conciencia de que las tecnologías inciden en el entorno cultural y político, así como en la adquisición de valores y criterios éticos evitando conductas socialmente negativas).

En este sentido, se entiende que los usuarios han desarrollado las competencias necesarias cuando son capaces de conocer, hacer y tener una actitud determinada tomando como referencia no solo los planos de conocimientos tecnológicos, sino también el componente social necesario para relacionarse en la red. Por tanto, gracias a las redes sociales virtuales se desarrolla la alfabetización múltiple y se convierten en un recurso educativo que utiliza tecnología como una herramienta para construcción del conocimiento a través de un aprendizaje colaborativo.

\section{7.- CONCLUSIÓN}

Actualmente, las redes sociales virtuales incorporan nuevas herramientas de comunicación que facilitan las tareas comunicativas entre el profesor y el estudiante. Las redes pueden funcionar como herramientas de aprendizaje muy importantes debido a su capacidad como gestores de conocimiento. Algunos ejemplos de ellos con un uso muy extendido son facebooks, fotologs y myspace.com, mientras que otros, como Hi5, Tuenti, Xing, LinkedIn, Twitter, Bebo y Orkut no son tan conocidos pero su capacidad de innovación y sobre todo de comunicación para fomentar una aprendizaje colaborativo adquiere un gran valor educativo. Por lo que sin duda, cada vez más se encontrarán como elementos importantes para promover la comunicación y la participación social.

Gros (2008, 273) destaca los aspectos de eficacia en el desarrollo del aprendizaje por parte de las redes sociales virtuales:

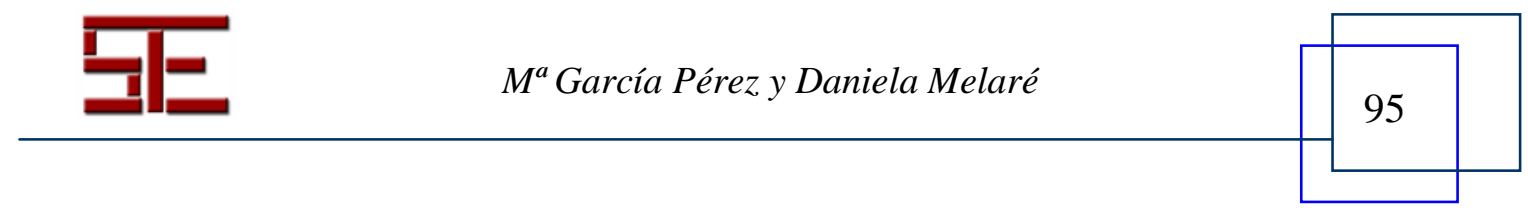




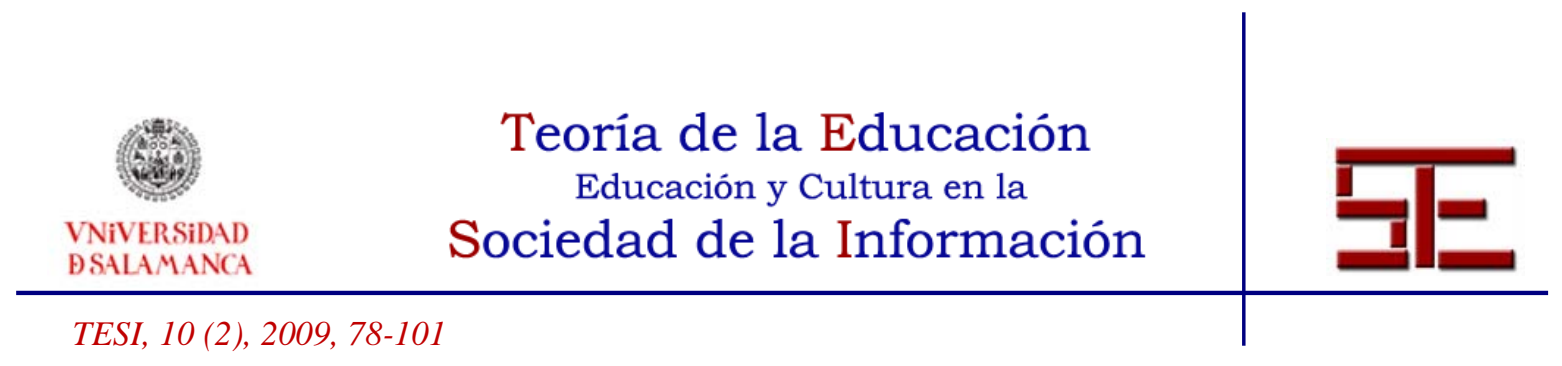

- "los docentes y administradores pueden compartir sus innovaciones y labor educativa.

- Las redes son fácilmente flexibles para organizar las actividades y luego incorporar las estructuras necesarias.

- Las redes cambian el significado del aprendizaje adulto.

- La red necesita coordinadores y animadores, por lo que existen muchas opciones de colaboración entre sus miembros.

- Las culturas basadas en la producción mutua de conocimientos, el aprendizaje y la colaboración reemplazan la transmisión de conocimiento de unas institución a otra. Las redes vinculan diferentes culturas, promueven el crecimiento y el desarrollo recíproco”.

La metodología de la enseñanza y el aprendizaje es un conjunto de decisiones motivadas que conducen a la obtención de valiosos efectos que caracterizan la acción educativa. La alfabetización múltiple se puede considerar la forma más adecuada para alcanzar valores sociales a través de la Red, desarrollo de destrezas en el uso de las tecnologías, objetivos educativos, y por su gran capacidad de formación dirigida a un gran número de usuarios.

Las herramientas digitales han servido tanto a los profesores y los estudiantes para mejorar su comunicación, pero la transmisión de información no es el único objetivo, es necesario crear contenidos educativos de la calidad adaptado a estos entornos, y tomar conciencia de estos avances tecnológicos-educativos por parte de los docentes.

Los contenidos educativos digitales deben cumplir con las características de eficacia y eficiencia adaptada al medio pero también al proceso educativo, sin olvidar su papel como objetos reutilizables adaptables al contexto y necesidades del estudiante. Los entornos virtuales son una alternativa dentro de las comunidades virtuales de aprendizaje para fomentar el aprendizaje colaborativo. Si se configura como un medio de aprendizaje, un medio dinámico, de manera que detecta las dificultades que puedan tener los estudiantes en el proceso de aprendizaje y la resolución de esos problemas de manera eficiente y con prontitud.

Una de las características básicas que deben percibir los docentes ante las redes sociales virtuales es que el nivel de conocimiento informático de sus alumnos no es homogéneo en sus grupos. Este es el comienzo para entender la forma de estructurar los elementos

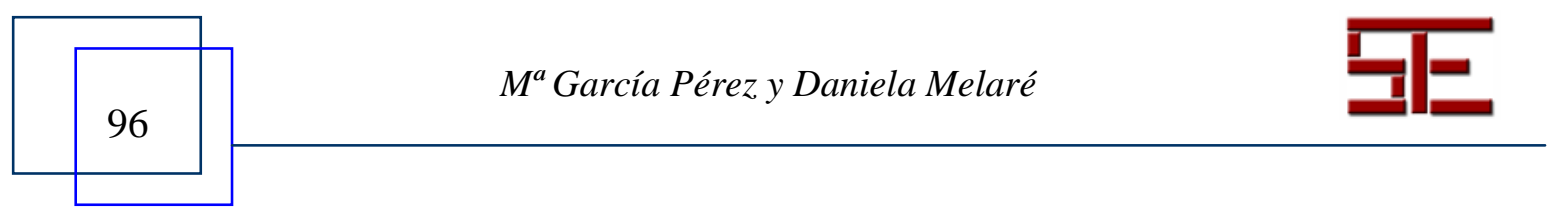




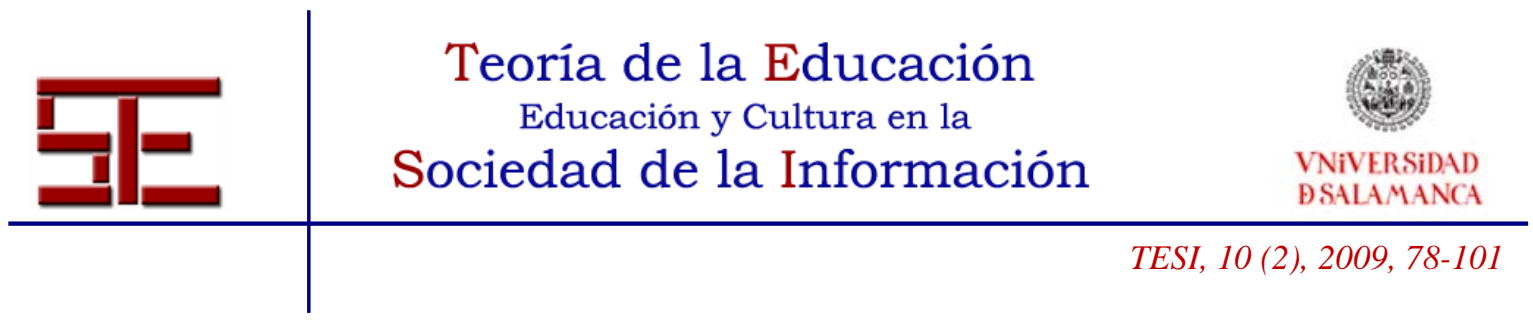

que componen el aprendizaje. La tendencia ahora es centrarse en el aprendizaje de los estudiantes a centrar sus necesidades y respetar sus dificultades.

Por otra parte, es necesario tener en cuenta las demandas de la sociedad actual, tanto personal como profesional. La actual formación requiere muchos conocimientos y habilidades, como el conocimiento de idiomas, de tecnología, desarrollo de la inteligencia personal, la creatividad, y la capacidad para trabajar en grupos, entre otras cosas. Los entornos virtuales con más frecuencia tienden a tener una amplia variedad de herramientas, pero se necesita un constante cambio hacia la actualización docente. Por esta razón es vital que los profesionales de la educación hayan desarrollado todas sus habilidades en el uso y beneficios que ofrecen las tecnologías para su labor docente.

Algunas de las propuestas educativas que se pueden destacar son:

- Los debates como método educativo son una herramienta esencial y se ha convertido en una fuente de desarrollo de competencias que fomentan las redes sociales virtuales.

- Las estrategias de enseñanza a través de actividades de participación y acciones que ayuden al alumno a asimilar los contenidos que hay que aprender. Estas estrategias implican acciones individuales y grupales, lo que fomentaría un desarrollo de nuevas capacidades. Se organizan en colaboración de grupos de trabajo con la ayuda de la tecnología.

- Reutilizar recursos educativos como un medio didáctico de enseñanza.

- Función evaluadora de este tipo de herramientas.

Las herramientas de comunicación de las redes sociales virtuales deben ser utilizadas con mayor énfasis para la enseñanza, deben ser un espacio para la resolución de dudas y análisis. Por tanto, es evidente que las redes sociales virtuales benefician a los usuarios, y que es de destacar su función socializadora, y el valor que añade a la participación y la colaboración. Sin duda son un buen apoyo para el aprendizaje y el desarrollo profesional, pero como hemos intentado demostrar, todavía queda mucho camino por recorrer y muchos docentes comprometidos con esta tarea.

\section{BIBLIOGRAFÍA}

BARBERÀ, E; y otros (2002) Pautas para el análisis de la intervención en entornos de aprendizaje virtual: dimensiones relevantes e instrumentos de evaluación. Instituto

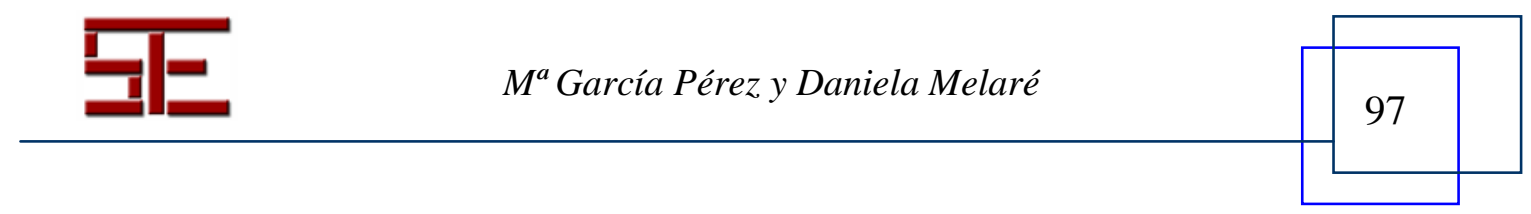




\section{\begin{tabular}{cc} 
Teoría de la Educación \\
Educación y Cultura en la \\
$\begin{array}{c}\text { VNiVERSIDAD } \\
\text { BSALAMANCA }\end{array}$ \\
\hline TESI, 10 (2), 2009, 78-101
\end{tabular}}

Interdisciplinario Internet, IN3. [en línea] Disponible en: http://www.uoc.edu/in3/dt/esp/barbera0704.pdf

BARROS, D. M.V. (2005) Tecnologias da inteligencia: gestão da competencia pedagógica virtual. Tese Doutorado. Unesp de Araraquara.

\section{BAWDEN, D. (2002). REVISIÓN DE LOS CONCEPTOS DE ALFABETIZACIÓN}

BELLUZZO, R. C. B. (2003) A formação contínua do professor na sociedade do conhecimento. Palestra proferida no dia 8/04/2003, na UNESP de Araraquara, no programa de pós-graduação em Educação Escolar.

BELLUZZO, R.C.B. ; BARROS, D.M.V. (2004) Pesquisas virtuais: metodologias e usos. In: BELLUZZO, R.C.B. Formação continuada de professores do ensino fundamental sob a ótica da information literacy, competência indispensável ao acesso à informação e geração do conhecimento. Transinformação, v.16, n.1, p.17-32, jan./abr.

BUSTOS, A.; COLL, C.; ENGEL, A.; AGUADO, G. (2005). De la contribución a la colaboración en comunidades virtuales de aprendizaje: la comunidad DIPE. V Congrés Multimedia Educatiu: Els reptes educatius de la societat digital. 29 de juny-1 de julio, Universitat de Barcelona, Barcelona. [en línea] Disponible en: http://www.ub.edu/grintie.

CABERO, J. (2006): “Comunidades virtuales para el aprendizaje. Su utilización en la enseñanza”, EDUTEC. Revista Electrónica de Tecnología Educativa, 20, [en línea]. Disponible en: http://edutec.rediris.es/Revelec2/revelec20/cabero20.htm

CABERO, J. y GISBERT, M. (2005): La formación en Internet. Guía para el diseño de materiales didácticos, Sevilla, Eduforma.

CAREAGA, B. M. C. (1996). Currículum cibernético: fundamentos y proyecciones. 1996. Xf. Tesis Magister Educación Universidad de Concepción, Chile. Disponível em: http://venado.conce.plaza.cl/ mcareaga/>.

CASADO, R. (Coord.) (2006). Claves de la Alfabetización Digital. Barcelona: Ariel, Fundación Telefónica.

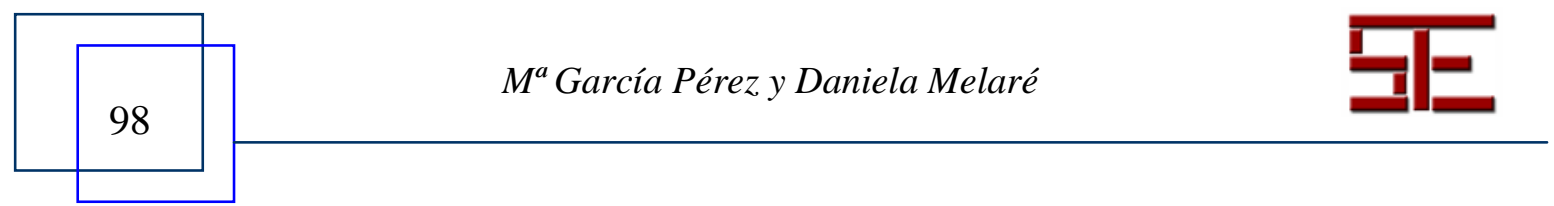




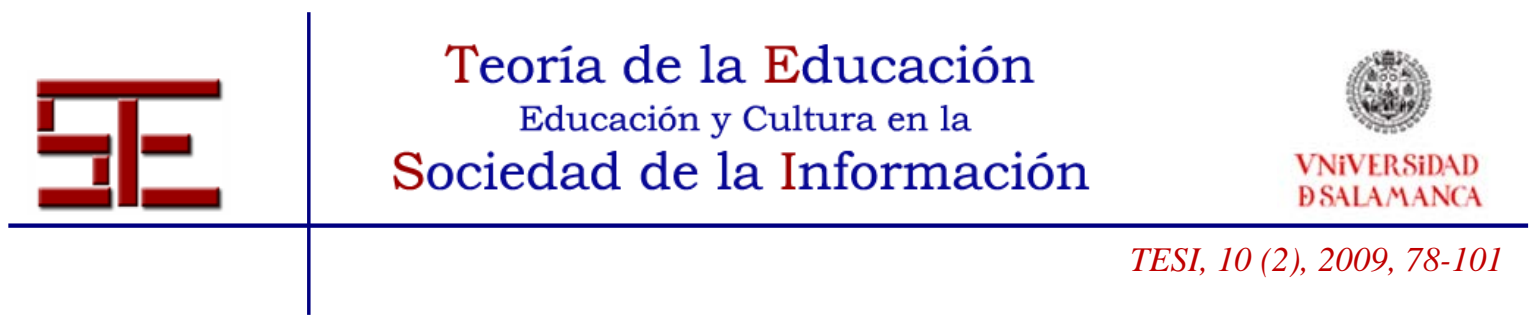

CEREZO, J. M. (coord); Fumero, A.; Roca, G.; Saez Vas, F. (2006). Web 2.0. Fundación Orange España.

COLL, C. (2004). Psicología de la educación y prácticas educativas mediadas por las tecnologías de la información y la comunicación: una mirada constructivista. Sinéctica, 25.

DUDZIAK, E. A. (2001) A Information literacy e o papel educacional das bibliotecas. Escola de Comunicação e Artes da Universidade de São Paulo.

DUDZIAK, E. A. (2001). A Information literacy e o papel educacional das bibliotecas. Mestrado em Ciências da Comunicação. Escola de Comunicação e Artes. Universidade de São Paulo, São Paulo.

GARCÍA ARETIO, L. RUIZ, M. y DOMINGUEZ, D. (2007): De la educación a distancia a la educación virtual, Barcelona, Ariel.

GARCIA PÉREZ, M (2007). Construcción social del conocimiento: análisis de la construcción social del conocimiento a través de las Redes Sociales de aprendizaje. Revista Comunicación y pedagogía: Nuevas tecnologías y recursos didácticos, 34-37 GROS, B (2008). Redes digitales y comunidades de práctica. XIV Congreso Nacional y II Iberoamericano de Pedagogía. Zaragoza.

HANNUM, N. (2001): Web-based traigning: advantages and limitations, en KHAN, B. (ed): Web-based traigning, New Jersey, Educational Technology Publications, 13-20.

HARASIM, L. (2003) Aprendizagem colaborativa (Mini Curso). In: X CONGRESSO INTERNACIONAL DE EDUCAÇÃO A DISTÂNCIA. Porto Alegre, Out. http://www.educared.net/congresoiv/docs/COMUNICACIONES/El\%20valor\%20de\%2 0la\%20participaci\%F3n\%20digital/ElValorParticipacionDigital_Comunicacion.pdf

INFORMACIONAL Y ALFABETIZACIÓN DIGITAL. Revista Anales de Documentación $\mathrm{n}^{0}$ 5, pp. 361-408

MARTÍNEZ, F. y PRENDES, M. P. (2006): Actividades individuales versus actividades colaborativas, en Cabero, J. y Román, P. (coods.): E-actividades, Sevilla, Eduforma, 183-202.

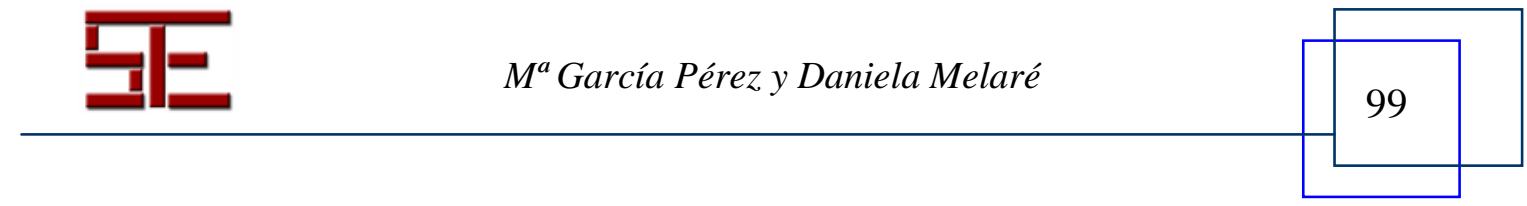




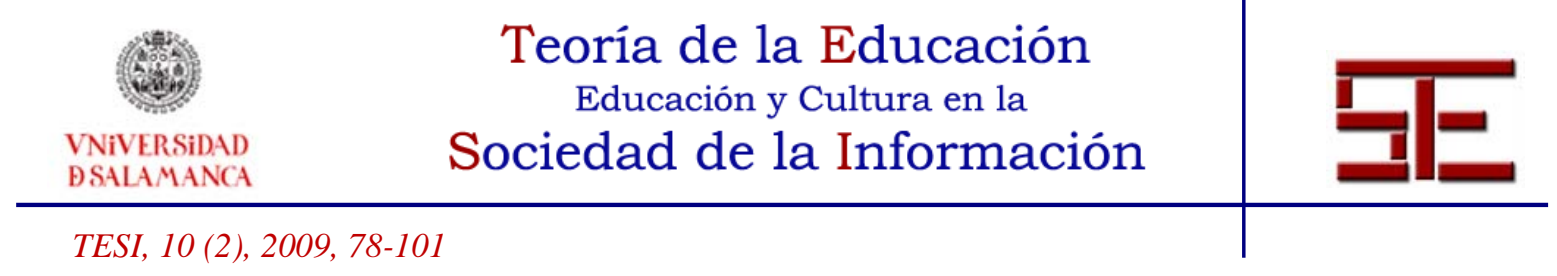

MONTES DE OCA, R. (2008). Alfabetización múltiple en nuevos ambientes de aprendizaje. México: Univ. J. Autónoma de Tabasco

MORAN, J.M.; MASETTO, M.T.; BEHRENS, M.A.(2000). Novas tecnologias e mediação pedagógica. Campinas: Papirus.

MORIN, E. (2000) Os sete saberes necessários à educação do futuro. São Paulo: Cortez.

PAPERT, S.(1987) Uma crítica ao tecnocentrismo no pensamento sobre a escola do Futuro. Conferência, Bulgária.

PERRENOUD, P.(1999) Construir competências desde a escola. Porto Alegre: Artmed.

PRENSKY, M. (2001). “Digital Natives, Digital Immigrants”. In On the Horizon, October 2001, 9(5) NCB University Press.

ROMÁN, P. (2004): Los entornos de trabajo colaborativo y su aplicación en la enseñanza, en Cabero, J. y Romero, R. (coods): Nuevas tecnologías en la práctica educativa, Granada, Aljibe, 213-256.

SALINAS, J. (1998): Redes y educación: Tendencias en educación flexible y a distancia. En PÉREZ, R. y otros: Educación y tecnologías de la educación. II Congreso Internacional de Comunicación, tecnología y educación. Oviedo. 141 - 151.

The Cocktail Analysis (2008). Herramientas de comunicación on-line: Las redes sociales. En línea. Disponible en: http://www.tcanalysis.com/uploads/2008/11/informe_observatorio_redes_sociales.pdf

TREJO DELABRE, R. (2005): «La persona en la Sociedad de la Información», citado en La Sociedad de la Información en el siglo XXI: un requisito para el desarrollo (Vol.2). Reflexiones y conocimiento compartido. Secretaría de Estado de Telecomunicaciones y para la Sociedad de la Información. [en línea]. Disponible en: http://www.desarrollosi.org/Volumen2/Web/PDF/Borrador_libro.pdf

TRINDADE, M. (2002). Literaria: teoria e prática orientações metodológicas. São Paulo: Cortez.

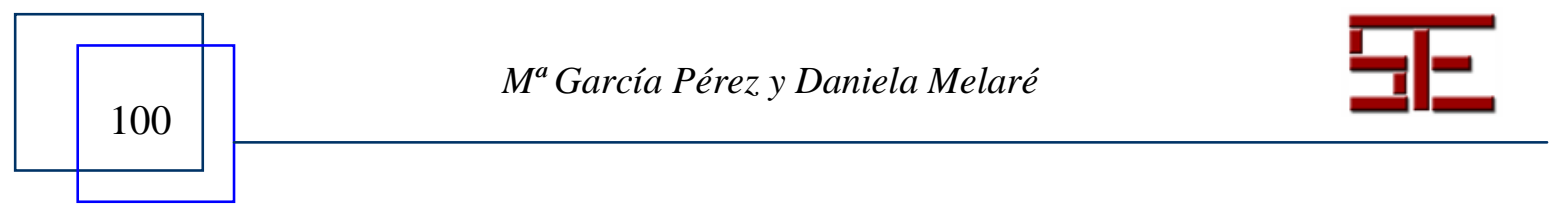




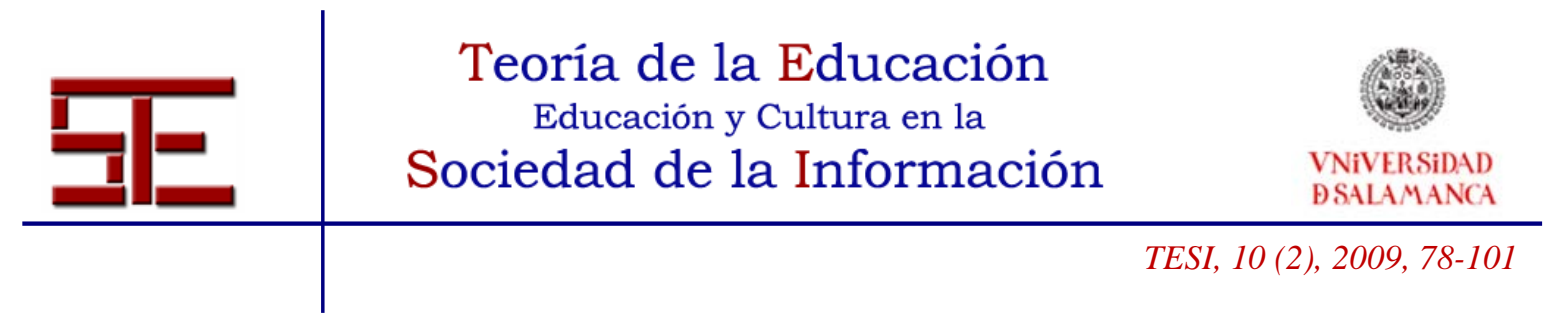

UNESCO (2008). Estándares de competencias en TIC para docentes. [en línea]. Disponible en: http://cst.unesco-ci.org/sites/projects/cst/default.aspx

WENGER, E. (2001) Comunidades de práctica. Aprendizaje, significado e identidad. Cognición y desarrollo humano, Coda II: comunidades de aprendizaje. (pp. 259-266) Paidos, Barcelona.

Para citar la presente editorial puede utilizar la siguiente referencia:

Melare, D. y García, M. (2009). Comunidades virtuales prácticas de alfabetización múltiple, en Ortega Sánchez, I. Ferrás Sexto, C. (Coord.) Alfabetización Tecnológica y desarrollo regional [monográfico en línea]. Revista Electrónica Teoría de la Educación: Educación y Cultura en la Sociedad de la Información. Vol. 10, n ${ }^{\circ}$ 2. Universidad de Salamanca [Fecha de consulta: $\mathrm{dd} / \mathrm{mm} / \mathrm{aaaa}]$

http://campus.usal.es/ revistas_trabajo/index.php/revistatesi/article/view/7509/7540

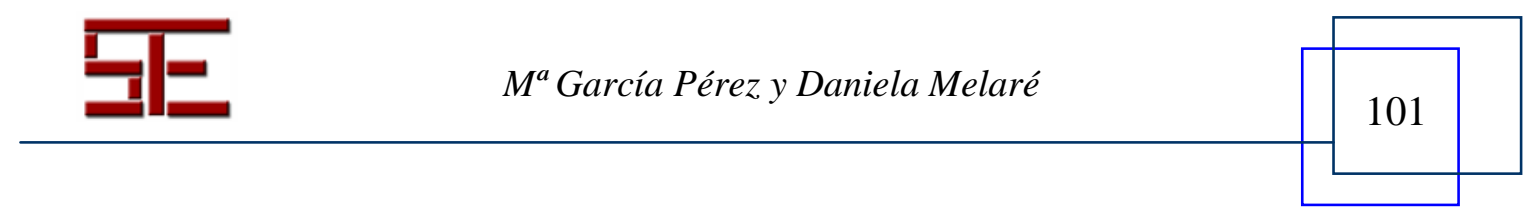

